\title{
Cross-platform application of a sea ice classification method considering incident angle dependency of backscatter intensity and its use in separating level and deformed ice
}

\author{
Wenkai Guo ${ }^{1}$, Polona Itkin ${ }^{1}$, Johannes Lohse ${ }^{1}$, Malin Johansson ${ }^{1}$, and Anthony Paul Doulgeris ${ }^{1}$ \\ ${ }^{1}$ Department of Physics and Technology, UiT The Arctic University of Norway \\ Correspondence: Wenkai Guo (wenkai.guo@uit.no)
}

\begin{abstract}
.
Wide-swath C-band synthetic aperture radar (SAR) has been used for sea ice classification and estimates of sea ice drift and deformation since it first became widely available in the 1990s. Here, we examine the potential to distinguish surface features created by sea ice deformation using ice type classification of SAR data. To perform this task with extended spatial and temporal coverage, we investigate the cross-platform transferability between training sets derived from Sentinel-1 Extra Wide (S1 EW) and RADARSAT-2 (RS2) ScanSAR Wide A (SCWA) and Fine Quad-polarimetric (FQ) data, as the same radiometrically calibrated backscatter coefficients are expected from these two C-band SAR platforms. For this, we use a novel sea ice classification method developed based on Arctic-wide S1 EW training, which considers the ice-type-dependent change of SAR backscatter intensity with incident angle (IA). This study focuses on the region near Fram Strait north of Svalbard to utilize expert knowledge of ice conditions from co-authors who participated in the Norwegian young sea ICE (N-ICE2015) expedition in the region. Separate training sets for S1 EW, RS2 SCWA and RS2 FQ data are derived using manually drawn polygons of different ice types, and are used to re-train the classifier. Results show that although the best classification accuracy is achieved for each dataset using its own training, different training sets yield similar results and IA slopes, with the exception of leads with calm open water, nilas or newly formed ice (the 'leads' class). This is found to be caused by different noise floor configurations of S1 and RS2 data, which lead to different IA slopes of this class. This indicates that dataset-specific re-training is needed for leads in the cross-platform application of the classifier. Based on the classifier thus re-trained for each dataset, the classification scheme is altered to target the separation of level and deformed ice, which enables direct comparison with independently derived sea ice deformation maps. The comparisons show that the classification of C-band SAR can be used to distinguish areas of ice divergence occupied by leads, young ice and level first-year ice (LFYI). However, it has limited capacity in delineating areas of ice deformation due to ambiguities in ice types represented by classes with higher backscatter intensities. This study provides reference to future studies seeking cross-platform application of training sets so they are fully utilized, and we expect further development of the classifier and the inclusion of other SAR datasets to enable image classification-based ice deformation detection using only satellite SAR data.
\end{abstract}


https://doi.org/10.5194/tc-2021-119

Preprint. Discussion started: 26 April 2021

(c) Author(s) 2021. CC BY 4.0 License.

\section{Introduction}

The general thinning of Arctic sea ice in recent decades has led to reduced internal strength (Landrum and Holland, 2020), which together with increased wind forcing (as indicated by atmospheric reanalyses) has caused accelerated ice drift speed (Spreen et al., 2011) and hence increased ice deformation (Rampal et al., 2009, 2011; Itkin et al., 2017). As surface features created by ice deformation, e.g. lead edges, rafted ice and pressure ridges, are the primary snow-trapping sea ice surface types (Liston et al., 2018), the shifting regime of Arctic sea ice deformation will directly impact snow accumulation on ice and thus affect heat fluxes through the ice layer, thereby influencing winter sea ice growth (Sturm et al., 2002). Also, sea ice deformation influences sea ice surface and bottom roughness and thus affects the transfer of momentum between atmosphere and ocean (Cole et al., 2017; Martin et al., 2016), preconditions the ice layer for more lateral melt (Arntsen et al., 2015; Hwang et al., 2017; Graham et al., 2019), and increases ice drift speed due to reduced floe sizes following ice break-ups (Toyota et al., 2006; Steer et al., 2008; Asplin et al., 2012). Additionally, ice deformation has a significant impact on ice primary productivity as it provides sheltered growth environment for ice flora and fauna in deformed ice (Gradinger et al., 2010; Fernández-Méndez et al., 2018; Graham et al., 2019) and favorable light conditions under lead ice (Assmy et al., 2017), creating biological hotspots. Reliable examination of sea ice deformation is therefore crucial for the evaluation and modeling of Arctic sea ice changes.

Sea ice deformation is traditionally estimated from spatial derivatives of sea ice motion using in-situ, air-borne and spaceborne data (e.g. Hutchings et al., 2011; Itkin et al., 2017, 2018; Bouillon and Rampal, 2015). However, consistent Arctic-wide monitoring of sea ice deformation can only be achieved through satellite remote sensing. Wide-swath synthetic aperture radar (SAR) data, e.g. RADARSAT-1 (RS1, 1995 to 2013), RADARSAT-2 (RS2, 2008 to present) and Sentinel-1A/B (S1, 2014 to present) data, have been commonly used to generate large-scale ice drift and deformation fields (e.g. Marsan et al., 2004; Komarov and Barber, 2014; Korosov and Rampal, 2017; Howell et al., 2018), benefiting from large spatial coverage and good temporal resolution. For example, the RADARSAT Geophysical Processor System (RGPS, (Kwok, 1998)) generates the most widely-used sea ice motion and deformation dataset using cross-correlation-based ice tracking on RS1 data for western Arctic from 1997 to 2008 (Raney et al., 1991). Data from other types of satellite sensors, e.g. visible, infra-red, and microwave radiometers and radar scatterometers, can also be used to generate ice drift fields with coarser resolution through feature tracking algorithms, for example those used by the National Snow and Ice Data Center (NSIDC) and the Ocean and Sea Ice Satellite Application Facility (OSI SAF) (Cavalieri et al., 2011; Lavergne, 2016; Dybkjaer, 2018).

In addition to sea ice deformation retrieval from ice motion, the potential of deriving areas of deformed and level ice as classes in wide-swath SAR image classification is valuable, as the automated or semi-automated nature of such methods permits fast processing of data with large spatial and temporal coverage. Various supervised and unsupervised sea ice classification methods have been developed based on SAR data, as reviewed by e.g. Zakhvatkina et al., (2019). Under the same radar parameters, the intensity of SAR backscatter on sea ice is the combined signal from several scattering mechanisms of which surface scattering is the dominant factor (Onstott, 1992; Moen et al., 2013). Surface scattering is in turn controlled by surface parameters including roughness and dielectric properties. Therefore, the separation of level and deformed ice, which has distinctly different surface roughness levels, is theoretically achievable through the classification of SAR backscatter intensities. 
https://doi.org/10.5194/tc-2021-119

Preprint. Discussion started: 26 April 2021

(c) Author(s) 2021. CC BY 4.0 License.

(c) (i)

Studies have isolated deformed ice using the classification of airborne and fully polarimetric, high-resolution satellite SAR data (e.g. Casey et al., 2014; Herzfeld et al., 2015), and linked sea ice roughness to wide-swath SAR backscatter intensities through correlation analyses, thus mapping sea ice deformation (Cafarella et al., 2019; Segal et al., 2020; Toyota et al., 2020). Gegiuc et al., (2018) estimated the degree of ice ridging from the classification of texture features from segmented RS2 ScanSAR Wide A (SCWA) data. However, no study has specifically targeted separating areas of level and deformed ice from the classification of backscatter intensities of wide-swath SAR data, such is the aim of this study.

This study investigates the feasibility of such a task with a terminal goal of Arctic-wide monitoring of sea ice deformation. In this context, a classification method consistently applicable to multiple satellite platforms with various spatial resolution, frequencies, and spatial and temporal coverage is desirable to utilize the advantages of each platform. This study is a first step towards this goal, which explores how the cross-platform application of a SAR image classifier between two C-band SAR platforms, S1 and RS2, is influenced by their comparative SAR characteristics. This is achieved by examining the transferability of training sets of various ice types between these two sensors in sea ice classification using manually derived reference polygons. These two SAR sensors are widely used for sea ice monitoring, and their wide-swath acquisition modes provide extensive spatial and temporal coverage for Arctic-wide sea ice analyses (Zakhvatkina et al., 2019). This transfer learning process is theoretically feasible as the two sensors are expected to yield the same radiometrically calibrated normalized radar cross section (backscatter coefficient, or $\sigma^{0}$ ) values for the same surface, as they operate at the same center frequency (5.405 $\mathrm{GHz}$ ). Studies have confirmed that these two sensors yield consistent ocean feature extraction results (Van Wychen et al., 2019), and other studies have used the fusion of coincident SAR data in different bands in sea ice classification (Dabboor et al., 2017; Lehtiranta et al., 2015). However, these two sensors differ in various other SAR parameters (Table 1, more details discussed in Section 2), thus requiring detailed examination of between-sensor differences in sea ice backscatter, and potential re-training in cross-platform application of SAR classifiers.

This study focuses this examination on sea ice surrounding the Norwegian young sea ICE 2015 (N-ICE2015) expedition north of Svalbard at the western end of the Transpolar Drift (Granskog et al., 2017, 2018), to utilize expert knowledge of co-authors who participated in the campaign in the process of training set derivation. The SAR classifier used for transfer learning is a newly developed sea ice classifier based on Arctic-wide training for S1 EW data (Lohse et al., 2020), which provides a novel solution to the effect of surface-type-dependent change of SAR backscatter intensity with incident angle (IA). The decrease of SAR backscatter intensity with IA is traditionally treated as an image property, and remedied by a global correction based on the approximate linear decrease rate in the log-domain (Zakhvatkina et al., 2019; Toyota et al., 2020). However, per-class IA correction is found to be necessary as the decrease rates (slopes of backscatter intensities versus IA, i.e. IA slopes) are different for different surface types (Gill et al., 2015; Liu et al., 2015; Mäkynen and Juha, 2017; Mahmud et al., 2018; Park et al., 2020). The classifier used in this study directly incorporates IA dependency of different ice types into a Bayesian classifier, which is achieved through the replacement of the constant mean vector of the Gaussian probability density function with a linearly variable mean. This shows significantly improved performance compared to classification of scenes with global IA correction. It is hereafter referred to as the Gaussian incident angle (GIA) classifier. 
https://doi.org/10.5194/tc-2021-119

Preprint. Discussion started: 26 April 2021

(c) Author(s) 2021. CC BY 4.0 License.

(c) (i)

Accordingly, the examination of the effect of sensor differences in the transfer of training will focus on different IA dependencies, mainly involving IA slopes, of ice surfaces between S1 and RS2 data. Specifically, this study mainly investigates training for $\mathrm{HH}$ and $\mathrm{HV}$ channels of wide-swath modes of both sensors, i.e. S1 EW and RS2 SCWA data, as the GIA classifier is trained on the two channels. RS2 FQ ( $\mathrm{HH}$ and $\mathrm{HV}$ ) data is also included to additionally investigate the use of its higher spatial resolution on the delineation of ice deformation features. Based on this examination, an optimal way of applying the GIA classifier to the local S1 and RS2 datasets can be found. All datasets are then classified, where the classification scheme is altered to specifically target the separation between level and deformed ice, thus allowing for direct comparison with areas of ice convergence and divergence produced by tracking drifting ice parcels.

In summary, this study has two specific objectives: 1. to evaluate the cross-platform transferability of training between S1 and RS2 data in the application of the GIA classifier in relation to IA slopes of different ice types, and derive an optimal way of applying the classifier to RS2 data; 2. to test to what extent sea ice type classification based only on backscatter intensities of $\mathrm{HH}$ and $\mathrm{HV}$ channels of C-band SAR data can be used to separate areas of level and deformed ice.

\section{Materials and methods}

\subsection{Study area and data}

The materials and methods of this study are summarized in a flowchart in Figure 1. This study mainly examines the crossplatform differences in IA slopes of sea ice types between RS2 SCWA and S1 EW data (hereafter referred to as S1 data as EW is the only acquisition mode of interest). The spatial resolution of these datasets is too coarse to detect individual leads and ridges less than approximately $100 \mathrm{~m}$ wide, but is sufficient for isolating leads several-hundred-meters wide, and separating areas dominated by deformed or level ice (Murashkin et al., 2018; Johansson et al., 2017). RS2 FQ data is also included in the analysis to provide a reference of classification performance of higher-resolution C-band SAR.

Several approaches are used to provide reference to the derivation of reference polygons for training and validation. Firstly, Sentinel-2 (S2, Level-2A Bottom Of Atmosphere (BOA) reflectance) and Landsat-8 (L8, Level-2 atmospherically corrected surface reflectance) data with less than $50 \%$ nominal cloud coverage are collected to provide optical coverage over the study area. Secondly, back-tracking of sea ice source regions from ice drift fields derived from passive microwave data (Itkin et al., 2017), as well as in-situ observations from co-authors who participated in the N-ICE2015 campaign, provide knowledge of the general spatial distribution of different ice types, especially first-year ice (FYI) and multi-year ice (MYI). Finally, the global sea ice type product from OSI SAF (10 km resolution), which provides separation between FYI and MYI using passive and active microwave scatterometers, is used as additional reference (OSI SAF, 2015). Very limited in-situ data is usable as reference data. Several helicopter-borne and airborne surveys overlap with RS2 FQ scenes, providing ice thickness and roughness, altimetry and photographs (Johansson et al., 2017; Singha et al., 2018), but their small areal coverage provides minimal support to this task, and are not used in this study.

This study mainly uses data covering the core of the 'winter' period after freeze-up and before melt onset, i.e. from January to April, as defined by Barber et al., (2001). This is to avoid the influence of wet snow on ice on radar backscatter which 


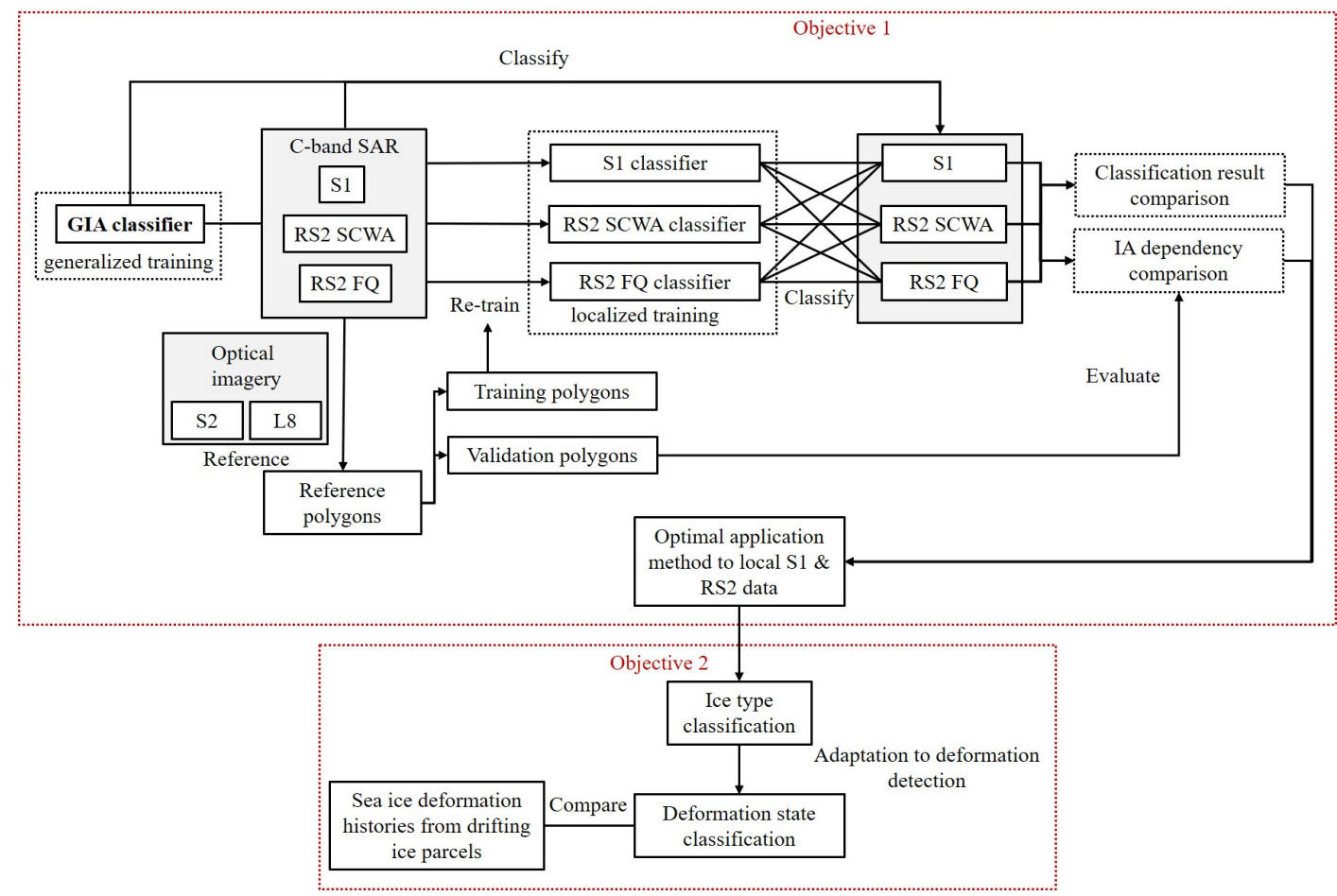

Figure 1. Flow chart of materials and methods used in this study.

reduces radar penetration depth and result in dominant backscatter from the air-snow or dry-and-wet-snow interface (e.g. Gill et al., 2015). Data covering the N-ICE2015 campaign is used as the primary dataset. SAR scenes with optical imagery overlap from 2016 to 2019 are also used to expand the dataset for re-training and validation. In-situ observations show that the sea ice area investigated during the N-ICE2015 campaign primarily consisted of a mixture of FYI and second-year ice (SYI, which belongs to the MYI category for the purpose of SAR-based sea ice classification), while other thinner ice types including nilas and young ice in leads also existed. Frost flower coverage of young ice was observed for the entire drift period of the campaign (Itkin et al., 2017; Johansson et al., 2017; Granskog et al., 2017, 2018; Singha et al., 2020). The terminology of sea ice classes used for classification in this study is defined in detail in Section 2.3.

Specifically, the following selection and masking processes are conducted on RS2 scenes:

1. The original GIA classifier has limited separating capacity between open water and sea ice, as IA slopes and backscatter intensities of open water in different sea states vary significantly, creating ambiguities with ice surfaces (Lohse et al., 2020). To mitigate this known issue and also to serve our purpose of separating level and deformed ice within pack ice, daily sea ice concentration data generated from SSMI/S (Special Sensor Microwave Imager/Sounder, DMSP F18 satellite) is used to filter out areas in RS2 SCWA scenes with ice concentration values of lower than $87 \%$. This is an empirically derived value for the removal of large, contiguous open water areas and the marginal ice zone. 
https://doi.org/10.5194/tc-2021-119

Preprint. Discussion started: 26 April 2021

(c) Author(s) 2021. CC BY 4.0 License.

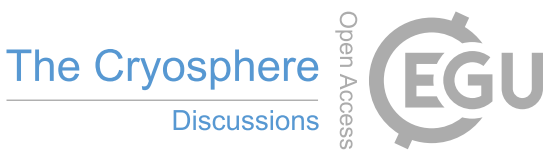
(c) (i)

Table 1. Parameters of satellite data used in this study. SGF: SAR Georeferenced Fine; SLC: Single Look Complex; GRD: Ground Range Multi-look Detected; Rng: range direction; Az: azimuth direction; NESZ: Noise-Equivalent Sigma Zero. Spatial resolution of S2 and L8 data are for bands 2, 3, and 4 .

\begin{tabular}{|c|c|c|c|c|c|}
\hline Parameters & RS2 SCWA & RS2 FQ & S1 EW & S2 & L8 \\
\hline Polarization & $\begin{array}{c}\text { Dual } \\
(\mathrm{HH}+\mathrm{HV})\end{array}$ & $\begin{array}{c}\text { Quad } \\
(\mathrm{HH}+\mathrm{VV}+ \\
\mathrm{HV}+\mathrm{VH})\end{array}$ & $\begin{array}{c}\text { Dual } \\
(\mathrm{HH}+\mathrm{HV})\end{array}$ & - & - \\
\hline Acquisition mode & SCWA & FQ & EW & - & - \\
\hline Product type & SGF & SLC & GRD & $\begin{array}{c}\text { Level-2A BOA } \\
\text { reflectance }\end{array}$ & $\begin{array}{c}\text { Level-2 surface } \\
\text { reflectance }\end{array}$ \\
\hline Nominal pixel spacing $[\mathrm{Rng} \times \mathrm{Az}](\mathrm{m})$ & $50 \times 50$ & $4.7 \times 5.1$ & $40 \times 40$ & - & - \\
\hline Nominal resolution $[\mathrm{Rng} \times \mathrm{Az}](\mathrm{m})$ & $\begin{array}{c}163-73 \times \\
78-106\end{array}$ & $5.2 \times 7.6$ & $93 \times 87$ & $10 \times 10$ & $30 \times 30$ \\
\hline Nominal scene size $[\mathrm{Rng} \times \mathrm{Az}](\mathrm{km})$ & $500 \times 500$ & $25 \times 25$ & $250 \times 250$ & $100 \times 100$ & $185 \times 180$ \\
\hline NESZ range (dB, approximate) & $-25--30$ & $-31--39$ & $-23--34$ & - & - \\
\hline IA range & $20^{\circ}-49^{\circ}$ & $18^{\circ}-49^{\circ}$ & $20^{\circ}-46^{\circ}$ & - & - \\
\hline Number of looks $[\mathrm{Rng} \times \mathrm{Az}]$ & $4 \times 2$ & $1 \times 1$ & $6 \times 2$ & - & - \\
\hline Date & \multicolumn{5}{|c|}{ Number of scenes } \\
\hline 20150108 & 1 & - & 1 & - & - \\
\hline 20150110 & 1 & - & 1 & - & - \\
\hline 20150112 & 1 & - & 1 & - & - \\
\hline 20150121 & 1 & - & 1 & - & - \\
\hline 20150126 & 1 & 1 & 1 & - & - \\
\hline 20150305 & 1 & 1 & 1 & - & - \\
\hline 20150319 & 1 & 1 & 1 & - & - \\
\hline 20150417 & 1 & - & 1 & - & 1 \\
\hline 20150419 & - & 3 & 1 & - & - \\
\hline 20150421 & 1 & - & 1 & 2 & 1 \\
\hline 20150423 & - & 2 & 1 & - & - \\
\hline 20150428 & 1 & 1 & 1 & - & 1 \\
\hline 20150430 & 1 & - & 1 & - & 2 \\
\hline 20190426 & 1 & - & 1 & 6 & - \\
\hline 20190430 & 1 & - & 1 & 3 & 1 \\
\hline
\end{tabular}


https://doi.org/10.5194/tc-2021-119

Preprint. Discussion started: 26 April 2021

(c) Author(s) 2021. CC BY 4.0 License.

(c) (i)

2. The RS2 scenes are further selected based on the availability of overlapping S1 data and optical imagery. For 2015, RS2 scenes with at least one overlapping S1 scene are kept for analysis. From 2016 to 2019, RS2 scenes with at least one S1 and one optical (S2 or L8) scene with significant near-coincident overlap (overlapping area $\geq 30 \%$ of the masked RS2 SCWA scene) are selected to ensure optical reference, resulting in only 2 RS2 SCWA scenes in 2019 (Table 1). The maximum time difference between overlapping RS2 data and S1, S2 and L8 data are 1 hour, 5.3 hours and 8 hours, respectively. These selection parameters are empirically determined judging from the data availability of each dataset corresponding to the RS2 scenes. The overlap analysis is conducted in Google Earth Engine (Gorelick et al., 2017), from which overlapping S1 scene IDs are derived and used for downloading using the Sentinelsat Python API, while RGB composites of S2 and L8 data (both from bands 4, 3 and 2) are directly generated and downloaded.

Pre-processing of RS2 and S1 data is performed using the SNAP software package (European Space Agency, 2020). All scenes are radiometrically corrected and calibrated to $\sigma^{0}$ values, so that RS2 and S1 data are directly comparable. For RS2 FQ scenes which are single look, $2 \times 2$ multi-looking is performed to reduce speckle and reach similar number of effective looks compared to S1 and RS2 SCWA scenes, while considering the preservation of linear features of interest, especially leads, within the scenes. Then, speckle filtering (Boxcar, $3 \times 3$ ) is applied on all SAR scenes, and backscatter intensities are converted to $\mathrm{dB}$.

Typically several S1 scenes overlap with each RS SCWA scene, but only one is selected to avoid redundancy. The first subswath of each S1 scene is removed for more reliable and inter-comparable classification results, as radiometric variations are especially pronounced between the first sub-swath and others (e.g. Park et al., 2019). The same masking process to erase pixels with low ice concentration is also conducted on S1 scenes. No further processing for S2 and L8 RGB composites is conducted, as these product are used qualitatively as reference data. The final list of satellite data used in this study is summarized in Table 1 (Gatti and Bertolini, 2015; Northrop, 2015; MacDonald Dettwiler Assoc. Ltd. (MDA), 2016, 2018), and the image boundaries of RS2 SCWA and S1 scenes are shown in Figure 2. Subsequent data analyses are performed using MATLAB (The Mathworks Inc., 2020) and Python (Van Rossum and Drake, 2009).

\subsection{Cross-platform application of the GIA classifier}

The original GIA classifier aims for Arctic-wide applicability, and thus has been trained on S1 scenes spread across the entire Arctic region from 2015 to 2019, in 'winter and early spring' months when ice is under freezing conditions (Lohse et al., 2020). Therefore, the class-specific IA dependencies in the classifier is produced from a generalized training set, and in theory encompass all IA dependencies of these classes found within this spatial and temporal domain. This study focuses on the transferability of training between S1 and RS2 data, for which we do not target Arctic-wide generalization. Instead, we focus on the N-ICE2015 region in winter 2015 to provide confidence to the validity of training and validation with input from expert knowledge, as mentioned above. Thus, we investigate the applicability of local training sets separately derived from S1 and RS2 scenes to both platforms, through which the between-sensor difference of sea ice backscatter can be assessed, and an optimal way of applying the GIA classifier on RS2 data can be derived. 


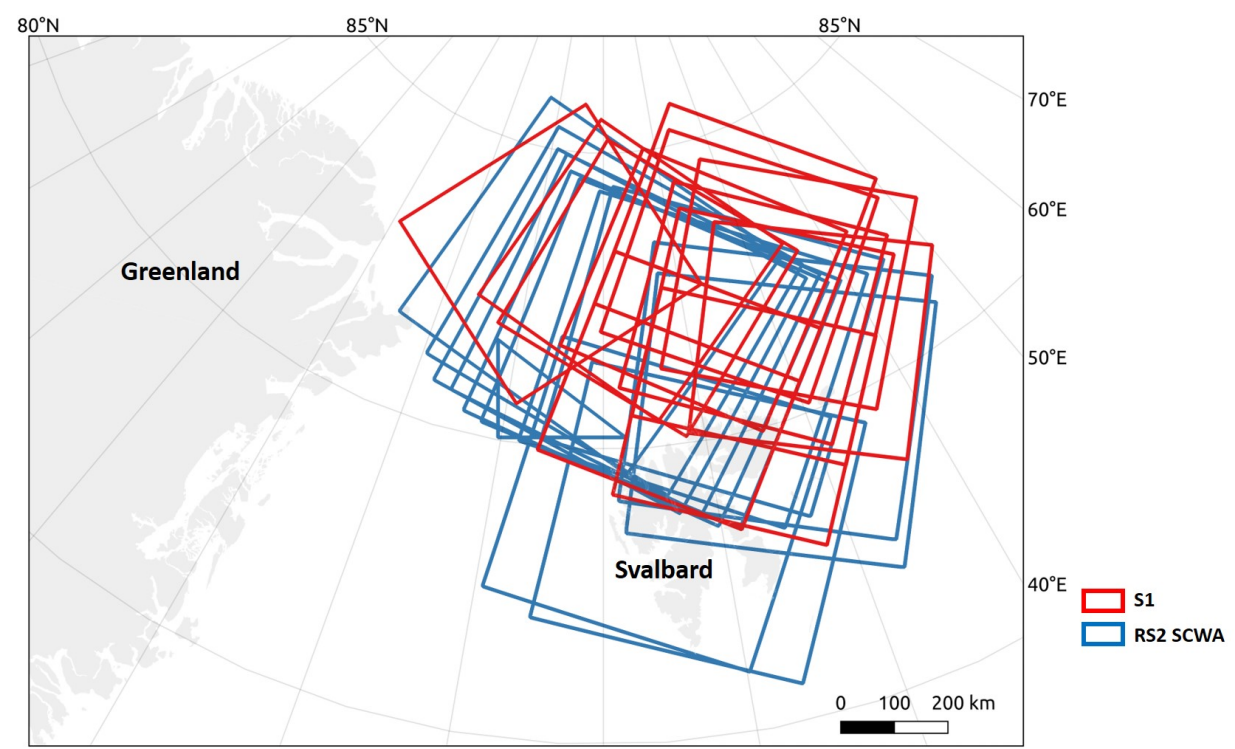

Figure 2. Boundaries of S1 and RS2 SCWA scenes used in this study.

For this purpose, reference polygons are derived for the SAR datasets based on visual examination of the scenes for retraining and validation. Polygons in the overlapping areas of corresponding RS2 SCWA and S1 scenes are used for both sensors, with manual adjustments accounting for their time difference (sea ice drift). This study uses the ice type classes in the original GIA classifier excluding the open water class, for reasons mentioned above. These classes are: leads, young ice, level FYI (LFYI), deformed FYI (DFYI), and MYI (explained in more detail in Section 2.3). The criteria for selecting the polygons are as follows:

1. Size: polygons of the same size within each dataset are used to standardize the outcome number of pixels in each class: $300 \mathrm{~m}$ by $300 \mathrm{~m}$ for RS2 SCWA and S1 scenes, and $30 \mathrm{~m}$ by $30 \mathrm{~m}$ for RS2 FQ scenes, which are approximately 3 times the respective effective pixel sizes given their number of looks. The choice of this standard polygon size takes into account typical widths of linear features, mainly leads and young ice;

2. Distribution: a minimum distance of 30 pixels is kept between reference polygons to achieve spatial balance and minimize spatial dependence between polygons of the same class. For each ice type, the polygons are distributed evenly across the entire range of IAs (where possible);

3. Numbers: in total, 100 polygons are delineated for each scene, and the same number (20) of polygons are selected for each class (where possible). As the 5 classes are usually uneven in spatial coverage, probability sampling, e.g. spatially random or systematic sampling, is not used to avoid under-representation of scarcely occurring classes.

For classes usually with small spatial coverage (leads and young ice) where criteria 2 and 3 cannot be both satisfied (i.e. small spatial coverage leading to inevitable selection of polygons in small areas), preference is given to criterion 3 to yield more polygons. Examples of reference polygons for S1 and RS2 SCWA scenes are shown in Figure 3. Reference polygons in 
https://doi.org/10.5194/tc-2021-119

Preprint. Discussion started: 26 April 2021

(c) Author(s) 2021. CC BY 4.0 License.

(c) (i)

each scene are randomly split in half, with the number in each class also split in half, for re-training and validation. Training polygons for all S1 scenes are merged into one training set (S1 training), and training polygons for all SCWA scenes and all FQ scenes are separately merged into two training sets (RS2 SCWA and RS2 FQ training, respectively). Thus, for each dataset (S1, RS2 SCWA or RS2 FQ), re-training incorporates IA dependencies from training polygons in all scenes. This is especially essential for RS2 FQ scenes where their small extents (spatial coverage: $25 \mathrm{~km}$ by $25 \mathrm{~km}$; IA range: $1.24^{\circ}$ to $1.94^{\circ}$ for our scenes) necessitate the combined investigation of IA dependencies across multiple scenes.

To evaluate cross-dataset transferability of training, the original GIA classifier is firstly applied to all datasets, providing a baseline for further analyses. Secondly, the training sets for S1, RS2 SCWA and RS2 FQ scenes are used to re-train the classifier to the study area for their corresponding datasets. The classifier with these different training sets are then applied to each dataset, and the results are evaluated using the validation polygons. Also, IA dependencies of different ice types as seen from validation polygons and classification results are examined. Based on these, the transferability of training between the datasets is assessed. Finally, based on this assessment, an optimal approach of applying the GIA classifier on RS2 data will be determined, supporting subsequent classification of ice types and also comparison to ice deformation.

\subsection{Adaptation to separate level and deformed ice}

Based on results from the above section, ice type classification is conducted on S1 and RS2 data in the study area. To separate level ice from areas of ice deformation and allow for direct comparison with ice deformation maps (see Section 2.4), the 5class classification scheme of the GIA classifier is altered to a 3-class one: deformed ice, level ice and others. This is hereafter referred to as the classification of 'deformation states,' and the correspondence between classes in the two schemes is listed as follows:

1. DFYI and MYI: deformed ice. The 5-class scheme involves both ice age and deformation state. An ideal classification of level and deformed ice requires separation between deformation states in every ice age category (mainly: young ice, FYI, and MYI). However, the GIA classifier does this only for FYI, such is common practice of SAR-based sea ice classification (e.g. see review by Zakhvatkina et al. (2019)). Specifically, the DFYI class refers to rough FYI with stronger C-band backscatter due to either ridging or the presence of other rough surface features, e.g. pancake ice.

MYI surface is usually rougher than younger ice types due to more accumulated deformation. The separation of MYI deformation states using SAR-based classification is challenging due to stronger presence of volume scattering from the desalinated and porous upper ice layer (increasing backscatter from level ice) as well as weathering of deformation features (decreasing backscatter from deformed ice) (Dierking and Dall, 2007; Dierking, 2008; Casey et al., 2014). As this study uses only C-band $\mathrm{HH}$ and $\mathrm{HV}$ intensities, this volume scattering component in MYI is significant, and the capacity of fully polarimetric data to distinguish between surface and volume scattering is not available (Moen et al., 2013; Casey et al., 2014). For the same reason, the contribution from volume scattering and ice deformation to strong SAR backscatter (characteristic of both DFYI and MYI) cannot be perfectly separated, creating ambiguities also between DFYI and MYI. Thus, although MYI is not necessarily physically associated with ice deformation, this study labels MYI together with DFYI as 'deformed ice.' 


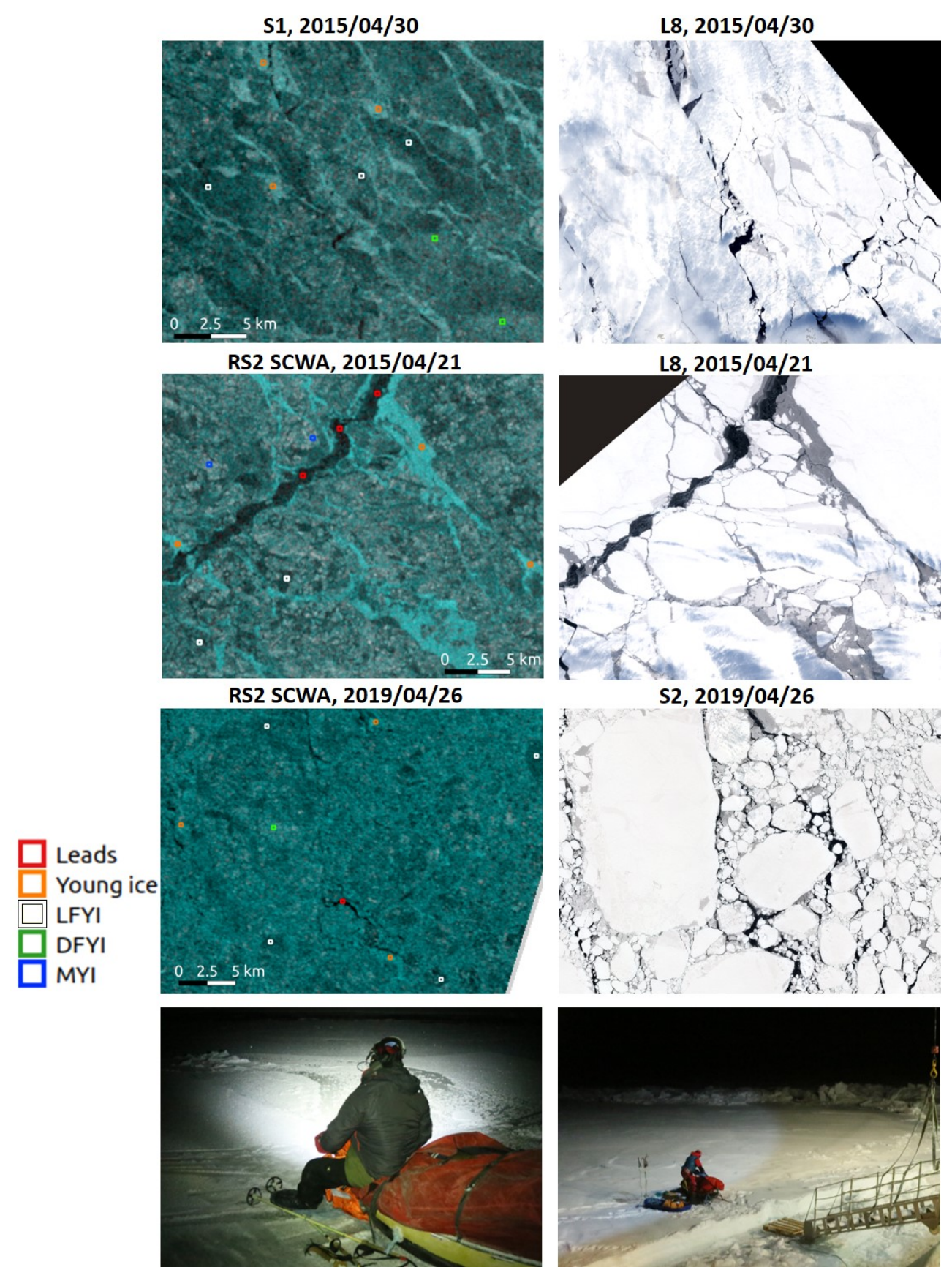

Figure 3. Examples of reference polygons in different ice types in overlapping parts of SAR and optical scenes, and example photographs of young ice witnessed in the N-ICE2015 campaign within the study area (bottom panel, credit: Dr. Polona Itkin). SAR images are shown in false-color RGB composites (R:HV, G:HH, B:HH). 
https://doi.org/10.5194/tc-2021-119

Preprint. Discussion started: 26 April 2021

(c) Author(s) 2021. CC BY 4.0 License.

(c) (i)

2. Young ice and LFYI: others. Among the many forms and stages of growth, the young ice class defined in the GIA classifier correspond to rough (in small-scale roughness) young ice covered by frost-flowers (mostly in re-frozen leads), thus having similar backscatter intensities to MYI. It has been demonstrated that typical deformation in young ice, i.e. ice rafting, is difficult to distinguish using C-band SAR (Dierking, 2010), and therefore cannot be included in the analysis. The experience from co-authors who participated in the N-ICE2015 campaign also shows that young ice in the study area experienced little rafting and were predominantly level with frost flower coverage, while ridging primarily occurred where young ice was in contact with thicker ice. Example photographs of young ice from the campaign are shown in Figure 3. Level young ice is not part of the 5-class scheme, as the LFYI class does not exclude level ice less than 30cm thick due to similar backscatter intensities (Dierking, 2008, 2010). As we are interested in ice deformation occurring on thicker ice, i.e. FYI and MYI, young ice is not labeled as deformed ice in the 3-class scheme, and is instead labeled 'others' along with LFYI.

3. Leads: leads. The leads class in the GIA classifier corresponds to ice openings occupied by calm open water, nilas or newly formed ice, thus having the lowest backscatter intensities. This class is of direct interest in the second goal of this study, and is labeled 'leads' in the 3-class scheme.

\subsection{Deformation parcel tracking}

Six pairs of S1 scenes from 21 to 26 January, 2015 (one image pair per day) surrounding the N-ICE2015 campaign is used to construct ice deformation histories for drifting ice parcels based on the sea ice drift algorithm developed by Korosov and Rampal (2017). Sea ice deformation is calculated from line integrals as described in e.g. Buollion and Rampal (2015) and Itkin et al (2017) and further filtered for noise. Sea ice drift is calculated on a $400 \mathrm{~m}$-regularly-spaced grid and deformation on the corresponding triangular grid. The deformation is classified to: no deformation, divergence and convergence. The rectangular parcels are initiated on the first day of the sequence on a regular grid with centroids spaced by $300 \mathrm{~m}$ and with a size 120 by $120 \mathrm{~km}$. Initially, all parcels are undeformed. For each next day the parcels move with the average velocity of the drift calculated inside of the $300 \mathrm{~m}$ radius around each parcel centroid. Each ice parcel accumulates at every step counts of each deformation class, based on the average value inside the $150 \mathrm{~m}$ radius from the centroid. Finally, based on the total number of counts, every parcel is classified into undeformed, predominantly convergence, predominantly divergence or a mix of both. Such Lagrangian parcel product is then gridded onto a $100 \mathrm{~m}$ grid, based on the nearest neighbor value. In the six days that the parcels are tracked, the ice pack undergoes vigorous deformation limited to several active linear kinematic features (LKFs). The effects of this recent deformation can then be visually compared with the classification results, thus examining the ability of the classification in recognizing the most recently formed surface features created by ice deformation. 
https://doi.org/10.5194/tc-2021-119

Preprint. Discussion started: 26 April 2021

(c) Author(s) 2021. CC BY 4.0 License.

(c) (1)

\section{Results and discussion}

\subsection{Cross-platform application of the GIA classifier}

\subsubsection{Classification accuracy and qualitative comparisons}

The classification accuracies (CAs) in Figure 4 show that for all datasets, local retraining leads to similar and significant improvements in classification performance over the original GIA classifier using Arctic-wide generalized training. Firstly, local training sets (Figure 4(a-c), columns S1, RS2 SCWA and RS2 FQ) yield average CAs significantly higher than the original GIA classifier (Figure 4(a-c), columns O), which is expected as local validation is used. Secondly, within each dataset, the local training sets yield similar overall CAs, despite the 'corresponding' training sets (Figure 4(a) column S1, (b) column RS2 SCWA, and (c) column RS2 FQ) yielding average CAs (87.63\%, 89.31\% and 91.70\%) higher than the rest (p-values shown in Figure 4). This corresponds well with our expectation of similar sea ice backscatter $\left(\sigma^{0}\right)$ for the two C-band sensors, while suggesting dataset-specific training can be used to achieve optimal overall accuracies.
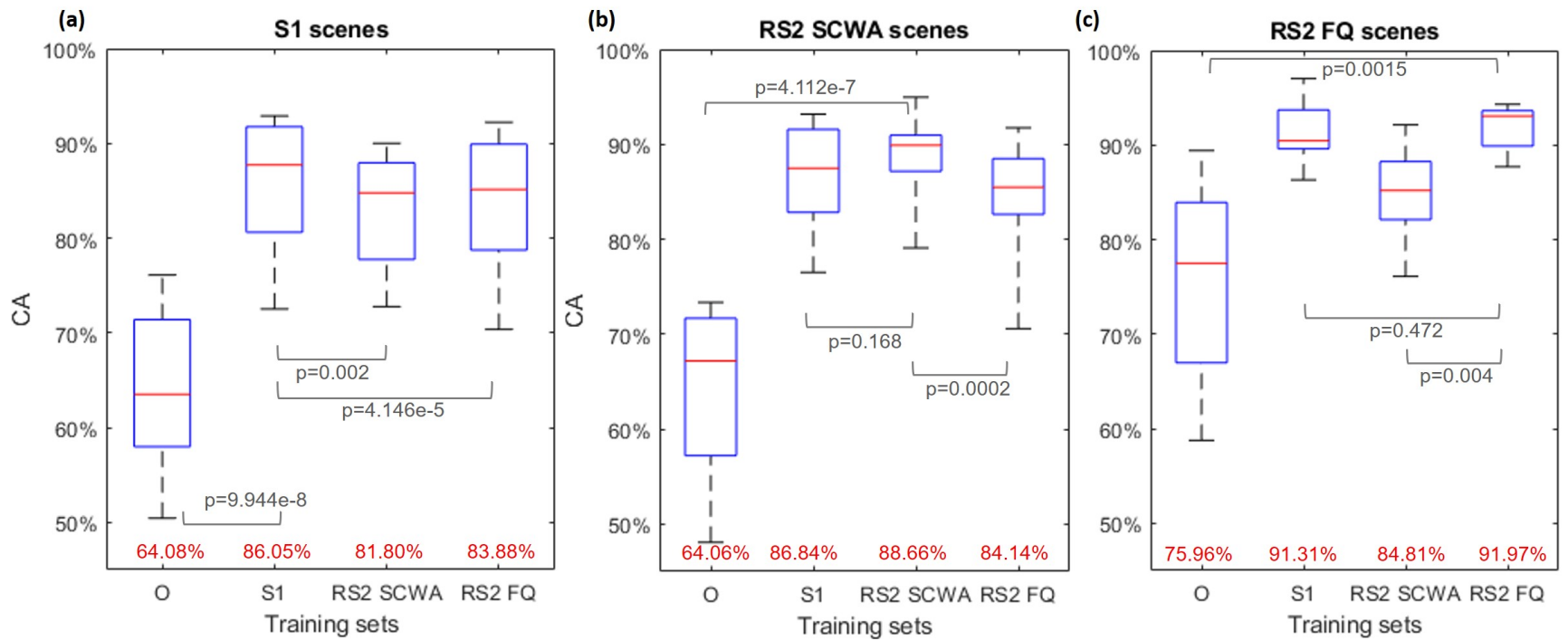

Figure 4. Classification CAs for S1, RS2 SCWA, and RS2 FQ scenes using the original and re-trained GIA classifier. O: training for the original GIA classifier; S1, RS2 SCWA, RS2 FQ: localized S1, RS2 SCWA and RS2 FQ training, respectively. Mean CAs are displayed in read below the box-plots. P-values of the difference in mean CAs are also shown.

Examples of qualitative comparison between results using the GIA classifier with different training are shown in Figure 5.

It can be seen that the original GIA classifier yields classification maps dominated by DFYI (green) and MYI (blue), while visual inspection of the SAR RGB composites (Figure 5 (a1-e1)) indicates significantly more prominent existence of the LFYI, rough young ice and leads. This is caused by frequent mis-classification of young ice as MYI and leads as LFYI. The three under-represented ice types (LFYI, rough young ice and leads) are better recognized by the locally re-trained GIA classifier 
https://doi.org/10.5194/tc-2021-119

Preprint. Discussion started: 26 April 2021

(C) Author(s) 2021. CC BY 4.0 License.

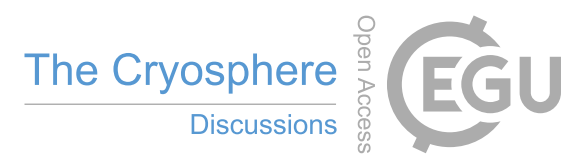

for all datasets (Figure 5(a3-e3; a4-e4; a5-e5)). This shows the expected improvement of classification performance from local

270 re-training as evaluated by local validation. The GIA classifier with different local training (Figure 5(a3-e3) vs. (a4-e4) vs. (a5e5)) yields results with similar spatial distribution of different ice types, and varies on the relative amount of pixels between classes.
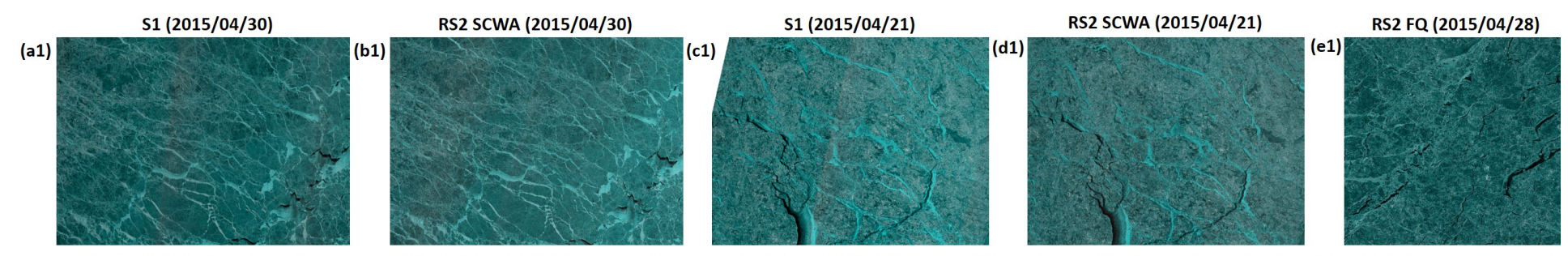

(a2)
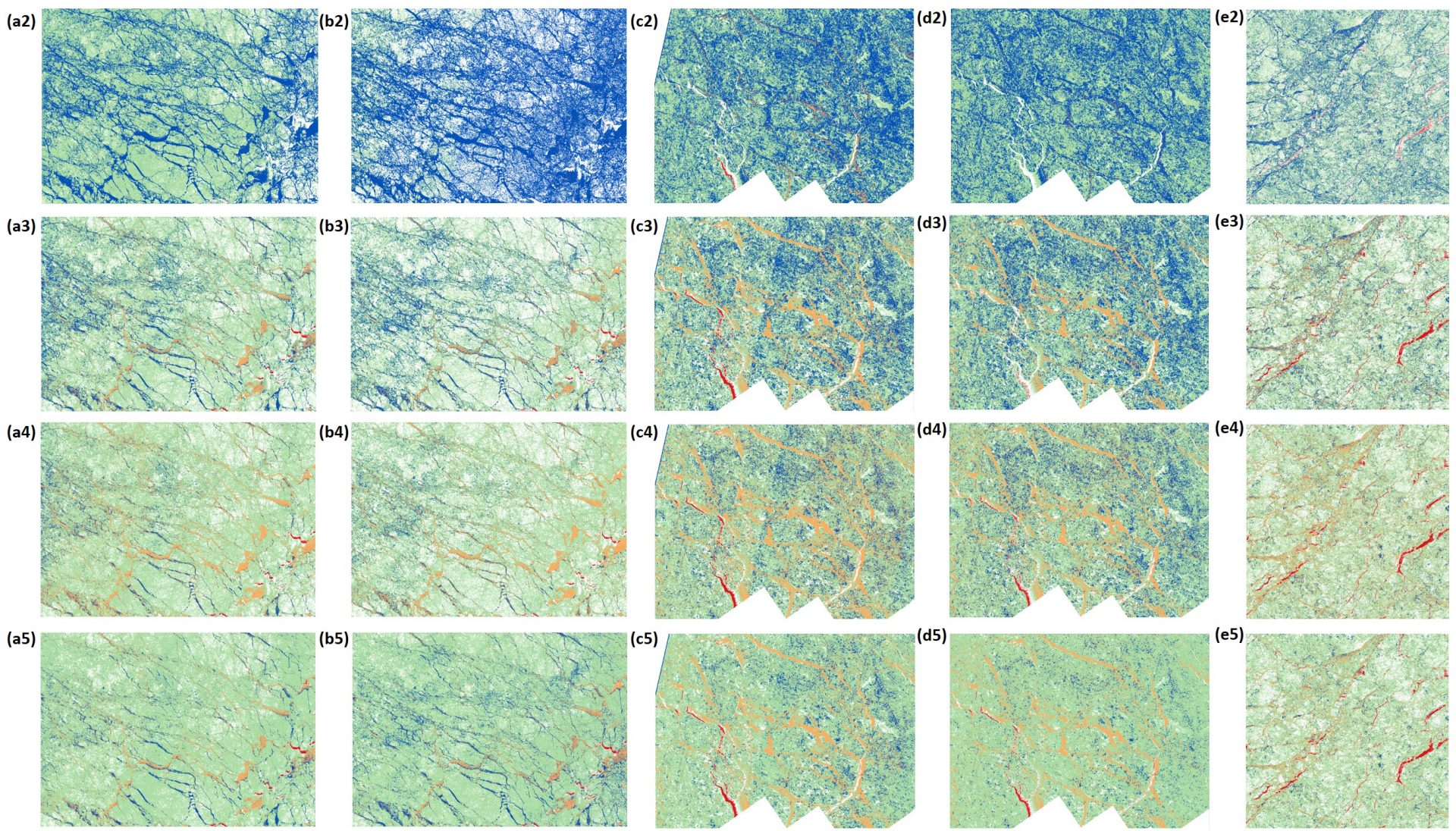

Leads $\square$ Young ice $\square$ LFYI $\square$ DFYI $\square$ MYI

Figure 5. Example comparison between classification results using the GIA classifier with different training. Columns (a) and (b): parts of S1 and RS2 SCWA scene, 2015/04/30; columns (c) and (d): parts of S1 and RS2 SCWA scene, 2015/04/21; column (e): RS2 FQ scene, 2015/04/28. (a1-e1): RGB composites; (a2-e2): classification using the original GIA classifier; (a3-e3), (a4-e4) and (a5-e5): classification using the GIA classifier re-trained using S1, RS2 SCWA and RS2 FQ training, respectively. 
https://doi.org/10.5194/tc-2021-119

Preprint. Discussion started: 26 April 2021

(c) Author(s) 2021. CC BY 4.0 License.

(c) (i)

\subsubsection{IA dependencies}

Theoretically, the performance of cross-dataset application of training is driven by the different IA dependencies of the ice types they record. To investigate this, scatter plots of $\mathrm{HH}$ intensities and IAs for different ice types are derived using the validations polygons (Figure 6). NESZ values across the IAs are generated from associated product files with the SAR data and plotted for comparison. Corresponding least-squares linear regression lines for different ice types are also plotted. HH-IA slopes derived from validation polygons as well as the original and re-trained (using corresponding training sets) GIA classifier are summarized in Table 2, with slope values from previous studies using winter C-band satellite SAR data listed for reference. For all datasets, the HV signals show less dependency on IA and is much more affect by noise, but its inclusion in the classifier has been demonstrated to improve class separations and increase classification performance (Lohse et al., 2020). For our study area, the difference in HV-IA dependencies provides additional separating capability between MYI and young ice, while those for leads, LFYI and DFYI are severely influenced by the configuration of the noise floors. Otherwise, the analysis of HV-IA dependencies provides little additional information relating to our objectives, and are not shown here.

The original GIA classifier (Figure 6(a2-c2)) yields similar separation between ice types across datasets, showing the characteristics of the generalized S1 training. Comparatively, the validation polygons yield different class separations (Figure 6(a1c1)) representing the local condition in the study area. The class separations and IA slopes of ice types from local training are reflected in the re-trained classification results (Figure 6(a3-c3, a4-c4, a5-c5)). The training set corresponding to each dataset (Figure 6(a3), (b4) and (c5)) produces class separation most similar to the validation polygons, as expected.

The comparative class separations and IA slopes from different training sets explain the above qualitative comparisons between the generalized and local training sets (Section 3.1.1): 1. the generalized training shows flatter HH-IA slopes and lower-extending HH values for LFYI which results in its strong overlap with leads (Figure 6(a2-c2)), while the localized training sets show steeper slopes for LFYI (Figure 6(a1-c1)), resulting in better separation between the two classes; 2. young ice and MYI are shown in all training sets to have similar HH intensities (Figure 6(a1-c1)), but show better separation in the HV channel for the local training sets than the generalized one (not shown), thus showing better separation after local re-training.

HH-IA slopes of different ice types are within the range of values reported by previous findings (Table 2), having considered that they are derived from different areas across the Arctic region. Comparative IA slopes for different ice types also conform to those reported in the literature: 1. IA slopes of DFYI are less than those of LFYI, as deformation features are strong scatterers which lead to higher standard deviation in backscatter intensities in small (local) IA intervals, and this added randomness in backscatter is not sensitive to IA; 2. compared to FYI, MYI has lower IA slopes due to the sensitivity of C-band radar signal to air bubbles in MYI, leading to substantial presence of volume scattering (when compared to SAR sensors at longer wavelengths, e.g. L-band), which is less sensitive to IA (Mäkynen et al., 2002; Dierking and Dall, 2007; Mahmud et al., 2018; Zakhvatkina et al., 2013; Mäkynen and Juha, 2017; Lohse et al., 2020). For each dataset, when compared to the original GIA classifier, the classifier re-trained using the corresponding training set yields slope values closer to the validation polygons, as expected. 
https://doi.org/10.5194/tc-2021-119

Preprint. Discussion started: 26 April 2021

(c) Author(s) 2021. CC BY 4.0 License.

Table 2. HH-IA slopes $\left(\mathrm{dB} /{ }^{\circ}\right)$ of different ice types derived in this and previous studies (SCN: ScanSAR Narrow; ASAR WS: Advanced Synthetic Aperture Radar, Wide Swath; QEI: Queen Elizabeth Islands).

\begin{tabular}{|c|c|c|c|c|c|c|c|c|}
\hline & & & & Leads & $\begin{array}{c}\text { Young } \\
\text { ice }\end{array}$ & LFYI & DFYI & MYI \\
\hline \multirow{3}{*}{ S1 scenes } & \multicolumn{3}{|c|}{ Validation polygons } & -0.120 & -0.203 & -0.306 & -0.287 & -0.153 \\
\hline & \multicolumn{3}{|c|}{ Original GIA classifier } & -0.146 & -0.155 & -0.179 & -0.255 & -0.106 \\
\hline & \multicolumn{3}{|c|}{ Re-trained classifier (S1 training) } & -0.130 & -0.233 & -0.290 & -0.265 & -0.150 \\
\hline \multirow{3}{*}{$\begin{array}{l}\text { RS2 SCWA } \\
\text { scenes }\end{array}$} & \multirow{3}{*}{\multicolumn{3}{|c|}{$\begin{array}{l}\text { Validation polygons } \\
\text { Original GIA classifier } \\
\text { Re-trained classifier (RS2 SCWA training) }\end{array}$}} & -0.065 & -0.230 & -0.272 & -0.202 & -0.147 \\
\hline & & & & -0.108 & -0.138 & -0.252 & -0.266 & -0.114 \\
\hline & & & & -0.058 & -0.242 & -0.251 & -0.243 & -0.149 \\
\hline \multirow{3}{*}{$\begin{array}{l}\text { RS2 SCWA FQ } \\
\text { scenes }\end{array}$} & \multirow{3}{*}{\multicolumn{3}{|c|}{$\begin{array}{l}\text { Validation polygons } \\
\text { Original GIA classifier } \\
\text { Re-trained classifier (RS2 FQ training) }\end{array}$}} & -0.241 & -0.161 & -0.230 & -0.225 & -0.092 \\
\hline & & & & -0.157 & -0.150 & -0.389 & -0.289 & -0.102 \\
\hline & & & & -0.272 & -0.169 & -0.225 & -0.219 & -0.073 \\
\hline Previous studies & $\begin{array}{l}\text { Data (No. of } \\
\text { scenes) }\end{array}$ & Time & Location & & & & & \\
\hline $\begin{array}{l}\text { Mäkynen et al., } \\
2002\end{array}$ & $\begin{array}{l}\text { RS1 SCN } \\
(42)\end{array}$ & $\begin{array}{l}\text { Feb-Apr } \\
\text { 1998-2002 }\end{array}$ & Baltic Sea & & & $\begin{array}{l}-0.19- \\
-0.34^{1}\end{array}$ & $\begin{array}{l}-0.12- \\
-0.30^{1}\end{array}$ & \\
\hline $\begin{array}{l}\text { Zakhvatkina et al., } \\
2013\end{array}$ & $\begin{array}{l}\text { ENVISAT } \\
\text { ASAR WS } \\
\text { (14) }\end{array}$ & $\begin{array}{l}\text { Winter } \\
\text { 2005-2006 }\end{array}$ & Various & & -0.167 & -0.255 & & 0.196 \\
\hline Gill et al., 2015 & RS2 FQ (9) & May 2018 & $\begin{array}{l}\text { Franklin Bay, } \\
\text { Canada }\end{array}$ & & & $\begin{array}{l}-0.25- \\
-0.33^{2}\end{array}$ & & \\
\hline Liu et al., 2015 & RS2 SCW (2) & Oct 2009 & Beaufort Sea & $-0.198^{3}$ & $-0.16^{4}$ & & & -0.134 \\
\hline $\begin{array}{l}\text { Mäkynen \& } \\
\text { Karvonen, } 2017\end{array}$ & S1 EW (33) & $\begin{array}{l}\text { Feb \& May } \\
2016\end{array}$ & Kara Sea & & & $\begin{array}{c}-0.25- \\
-0.26\end{array}$ & $\begin{array}{c}-0.23- \\
-0.24\end{array}$ & \\
\hline $\begin{array}{l}\text { Mahmud et al., } \\
2018\end{array}$ & $\begin{array}{l}\text { RS2 SCW } \\
(45)\end{array}$ & $\begin{array}{l}\text { Feb-Mar } \\
2009-2010\end{array}$ & QEI, Canada & & & 0.32 & 0.22 & $\begin{array}{c}-0.14- \\
-0.19\end{array}$ \\
\hline Lohse et al., 2020 & S1 EW (-) & $\begin{array}{l}\text { Winter } \\
2015-2019\end{array}$ & Arctic-wide & & & -0.27 & & -0.23 \\
\hline
\end{tabular}

${ }^{1}$ Slopes of FYI with dry snow on top.

${ }^{2}$ Slopes of land-fast smooth FYI with thin $(7.7 \pm 3.9 \mathrm{~cm})$ to thick $(36.4 \pm 12.3 \mathrm{~cm})$ snow cover.

${ }^{3}$ Slope of Nilas.

${ }^{4}$ Slope of deformed gray ice. 
https://doi.org/10.5194/tc-2021-119

Preprint. Discussion started: 26 April 2021

(c) Author(s) 2021. CC BY 4.0 License.
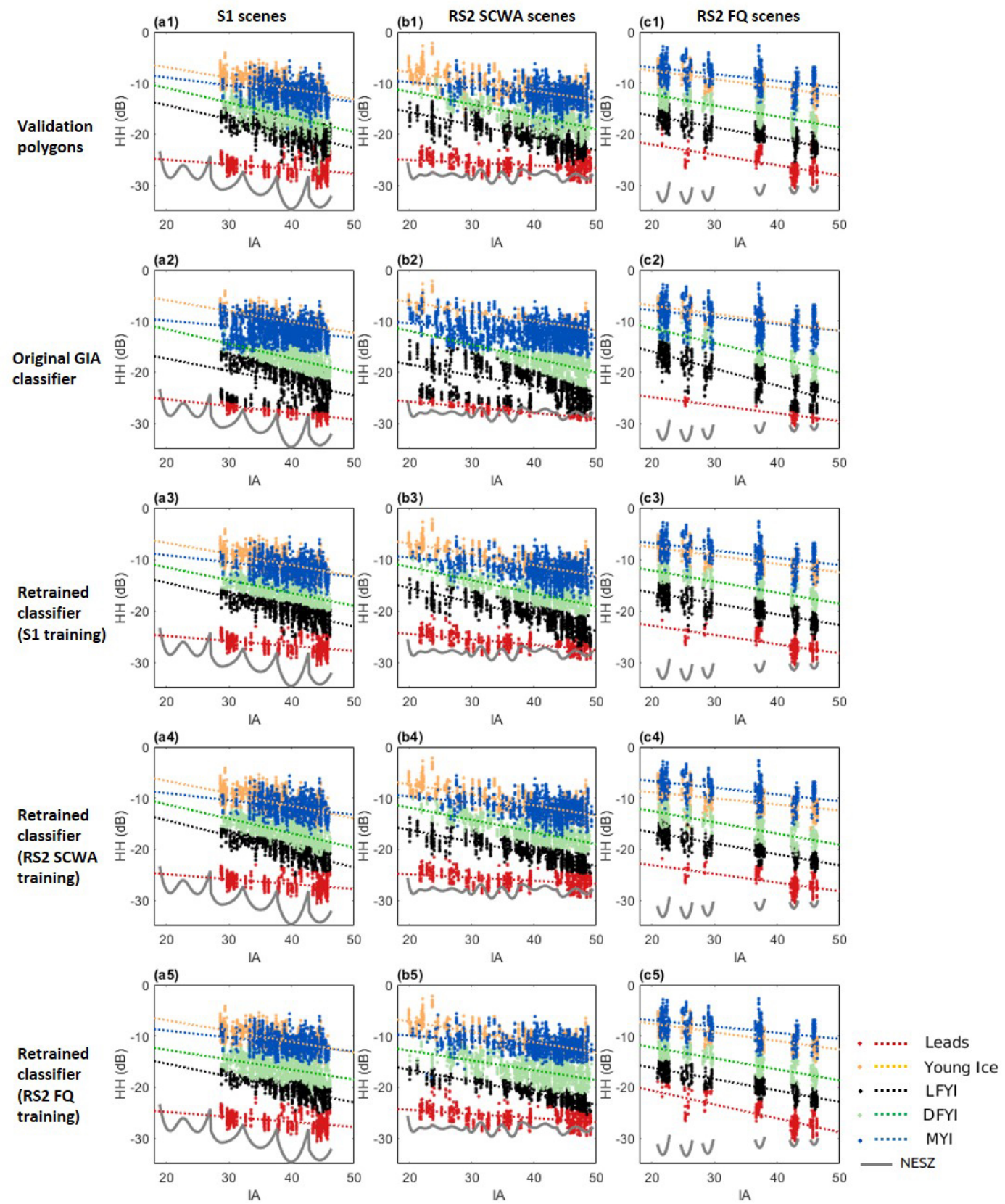

Figure 6. HH-IA scatter plots, least-squares regression lines for different ice types, and NESZ values for different datasets.

\subsubsection{Leads and noise floors}

Between the two wide-swath datasets (S1 EW and RS2 SCWA), the IA slopes for young ice, FYI and MYI follow similar trends (Figure 6, columns (a) and (b)). However, the IA slope for the leads class in the RS2 SCWA training is visibly flatter than that 
https://doi.org/10.5194/tc-2021-119

Preprint. Discussion started: 26 April 2021

(c) Author(s) 2021. CC BY 4.0 License.

(c) (i)

in the $\mathrm{S} 1$ training, which is confirmed by their respective slope values shown in Table $2\left(-0.12 \mathrm{~dB} /{ }^{\circ}\right.$ for $\mathrm{S} 1$ and $-0.065 \mathrm{~dB} /{ }^{\circ}$ for

RS2 SCWA). It can be seen from the plotted NESZs that the leads class for S1 scenes is above the noise floor throughout the IA range (Figure 6(b1)), while for RS2 SCWA scenes (with a flatter noise floor), it is very close to and reaches the noise floor at an approximate IA of $30^{\circ}$ (Figure 6(b2)). This explains the flatter IA slope for leads in RS2 SCWA scenes.

For the RS2 FQ scenes, IA slopes for the young ice, FYI and MYI (Figure 6(c1)) are similar to the wide-swath datasets. The RS2 FQ scenes are all well within pack ice, and the leads that these scenes additionally recognize due to higher spatial resolution (compared to wide-swath scenes) are very narrow and scarce. Therefore, the multi-looking and speckle filtering processes has mixed the pixel values in narrower leads to surrounding pixels with higher backscatter intensities, resulting in small numbers of reference polygons. This has prevented full evaluation of its IA dependency due to uneven representation across IAs, and compromises the validity of IA dependencies recorded by this class. However, the existing reference polygons show that HH intensities of RS2 FQ leads pixels do not reach the noise floor across the IA range, and therefore does not present the above issue in the RS2 SCWA training.
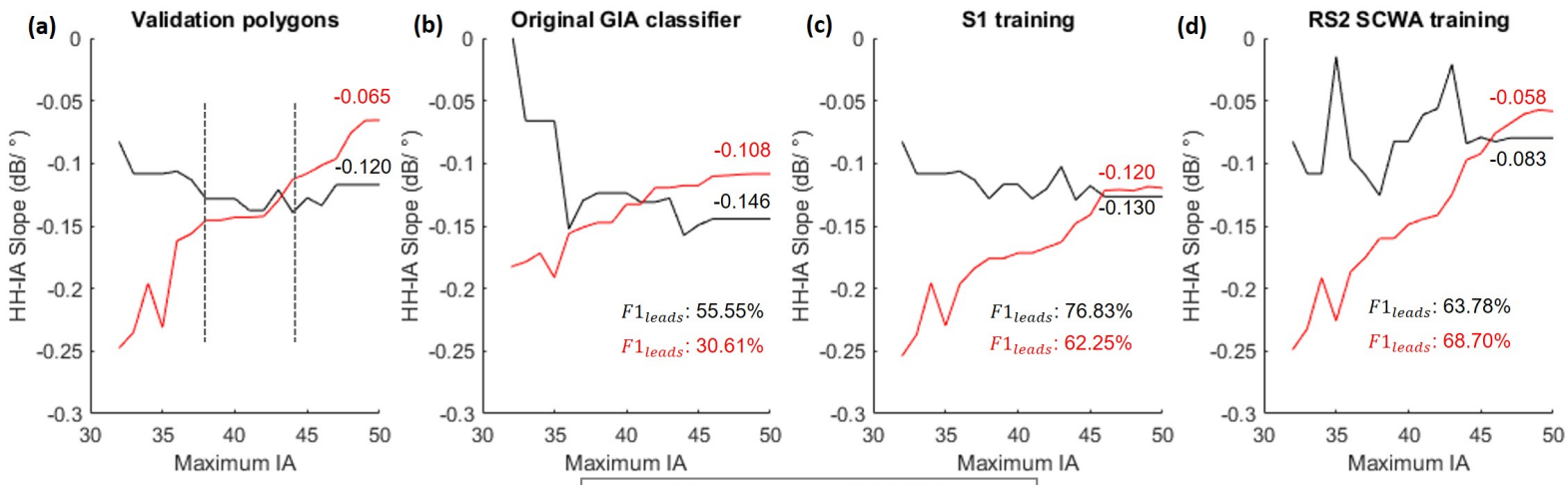

Figure 7. HH-IA slopes for different IA maximums and F1 scores of the leads class, with the overall slopes (maximum IA = 50) shown in corresponding colors (black: S1 scenes; red: RS2 SCWA scenes).

To further investigate the interaction between the leads class and respective noise floors of the sensors, IA slopes for leads from the near range to increasing IA maximums are plotted in Figure 7. F1 scores of the leads class, which combines producer's and user's accuracies, are also shown to evaluate the overall accuracies of this class. It can be seen that S1 validation polygons show relatively constant HH-IA slopes across the range of IA maximums (in black). For RS2 SCWA scenes (red), the slopes are steeper (higher absolute values) for IA maximums in the near range, and stabilizes after reaching a similar slope level to $\mathrm{S} 1$ scenes (at approximately -0.16 to $-0.12 \mathrm{~dB} /{ }^{\circ}$, at IA maximums from $38^{\circ}$ to $44^{\circ}$, as shown between the dashed lines). The slopes then quickly flattens (lower absolute values) as the IA maximum approaches the far range, eventually reaching a much flatter overall slope of $-0.065 \mathrm{~dB} /{ }^{\circ}$ compared to $-0.120 \mathrm{~dB} /{ }^{\circ}$ for $\mathrm{S} 1$ scenes. This confirms the findings from Figure $6(\mathrm{a} 2)$ where the leads pixels reach the noise floor at approximately $30^{\circ}$, and remains at at a similar $\mathrm{dB}$ level due to the presence of the noise 
https://doi.org/10.5194/tc-2021-119

Preprint. Discussion started: 26 April 2021

(c) Author(s) 2021. CC BY 4.0 License.

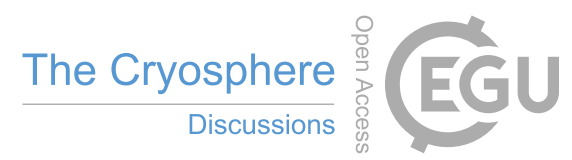

floor. Thus, using the S1 training on RS2 SCWA scenes will inevitably introduce IA dependency for leads that does not fit the RS2 SCWA dataset, and vice versa.

For the classification results (Figure 7(b-d)), the training used by the original GIA classifier yields different overall IA slopes than the local validation for leads in both datasets, resulting in relatively low classification accuracies, as shown by the F1 scores (Figure 7(b), $\left.F 1_{\text {leads }}\right)$ ). When applied to their corresponding datasets, the local S1 and RS2 SCWA training sets (Figure 7(c), black; Figure 7(d), red) yield HH-IA slopes across IA maximums similar to their respective validation polygons (Figure 7(a)). Comparatively, cross-platform application of training sets (Figure 7(c), red; Figure 7(d), black) produces lower accuracies, confirming the findings above.
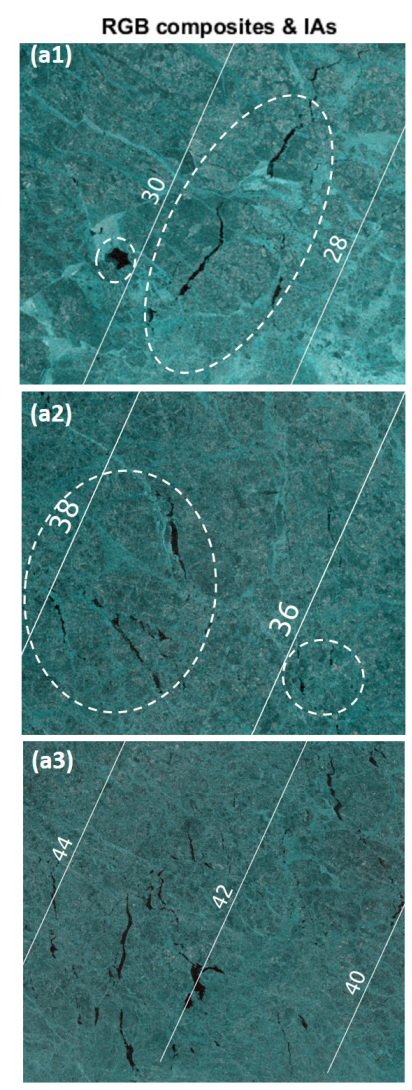

Original GIA classifier
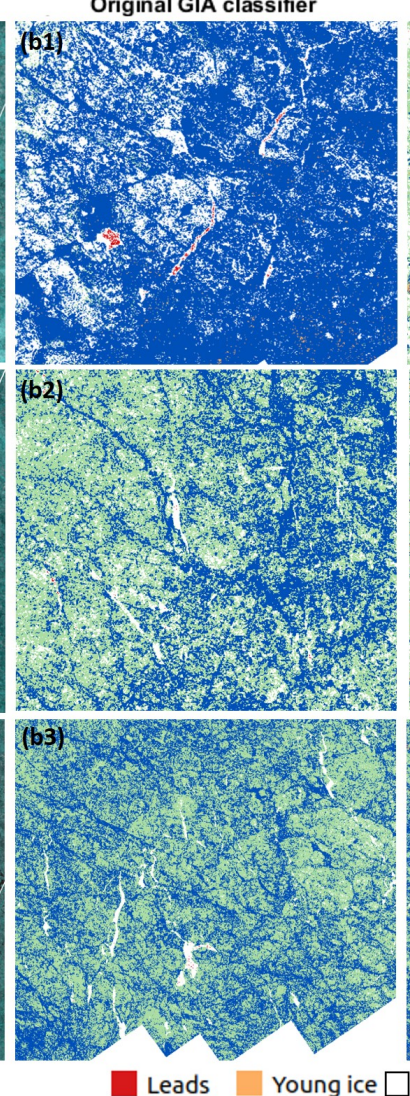

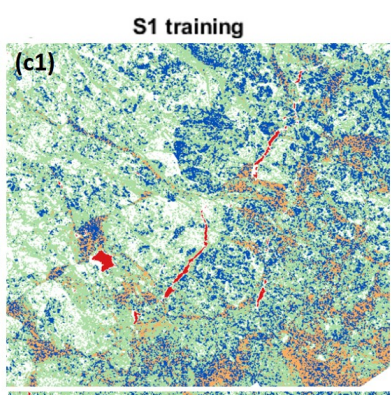

(c2)
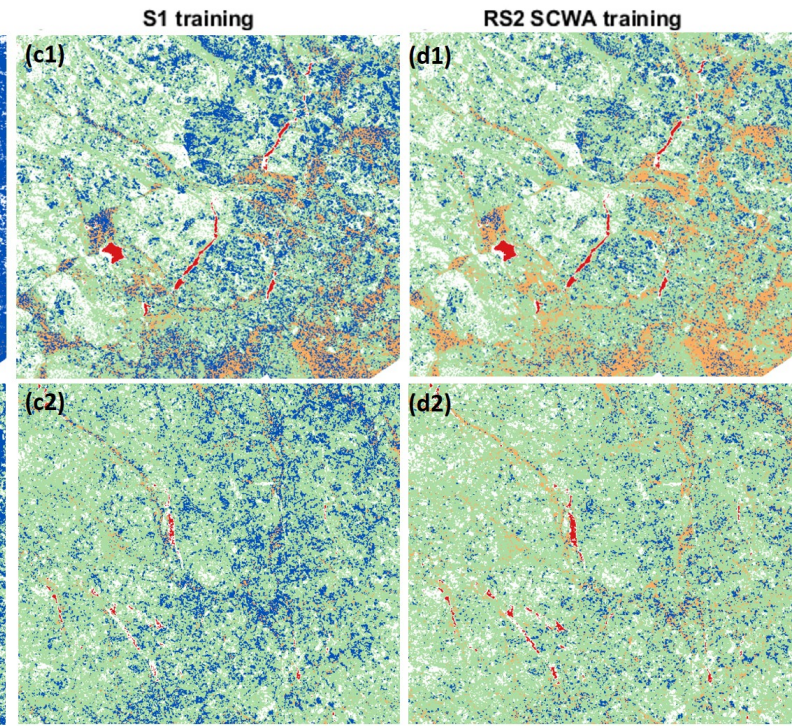

(d2)
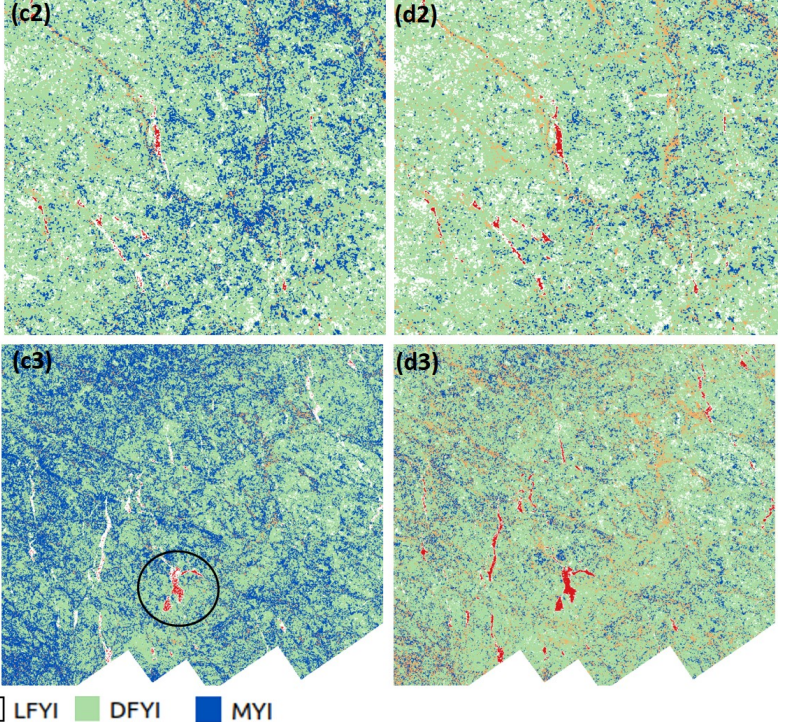

Figure 8. Comparison of classification results in different IA ranges for the RS2 SCWA scene on 2015/03/05, where IA contours with values are shown in white, and main areas containing the leads class are circled in white in (a1-a3).

To inspect this effect in classification maps, an example is given in Figure 8 which shows the difference between the GIA classifier with different training in recognizing leads in different IA ranges. For the near range, the GIA classifier with local re-training (Figure $8(\mathrm{c} 1)$ and (d1)) yields very similar spatial coverage of leads. In IAs between $34^{\circ}$ and $39^{\circ}$, classification using the RS2 SCWA training (Figure $8(\mathrm{~d} 2)$ ) produces a more complete representation of the leads than the S1 training (Figure 8(c2)) 
https://doi.org/10.5194/tc-2021-119

Preprint. Discussion started: 26 April 2021

(c) Author(s) 2021. CC BY 4.0 License.

(c) (i)

where parts of the leads are identified as LFYI. In IAs between $40^{\circ}$ and $45^{\circ}$, the RS2 SCWA training preserves all visible leads (Figure 8(d3)) while the S1 training keeps only part of the main ice opening (Figure 8(c3), circled in black) but almost entirely misses the other leads. This gradual increase in mis-classification of leads as LFYI with IA corresponds well with Figure 6 (column (b)): the stronger HH-IA dependency for leads in S1 training (steeper IA slopes than RS2 SCWA training) yields the same leads-LFYI separation in the near range, but shows gradually more mis-classification of leads to LFYI (Figure 6(b3) compared to (b4)) in IAs greater than approximately $37^{\circ}$. The same is true for RS2 SCWA training when used to classify S1 scenes (Figure 6(a4) compared to (a3)), where its flatter HH-IA slope leads to mis-classification of LFYI to leads in the far range.

From the above analyses of CAs, HH-IA dependencies and qualitative comparisons, it can be concluded that in our study area and based on the GIA classifier, S1 and RS2 SCWA training sets are not directly transferable, mainly due to the known potential of mis-classification between LFYI and leads. This is caused by the different interactions between backscatter from leads and the noise floor in the two datasets, i.e. the flattened IA slope of leads in RS2 SCWA data due to contact with the higher noise floor. The RS2 FQ scenes yield similar IA slopes for classes other than leads compared to the wide-swath datasets, while full assessment of the leads class is impeded by the lack of reference polygons. Re-training to the study area also increases performance of the GIA classifier when applied to S1 scenes. Based on these assessments, the S1, RS2 SCWA and FQ scenes are classified using the GIA classifier locally re-trained using their corresponding training sets, and are used for the following comparison to ice deformation.

\subsection{Comparison between classification results and deformation parcels}

The five ice types in the classification results are summarized into three deformation states, as mentioned above, and are compared with the deformation parcels derived from S1 data (Figure 9). Deformation accumulated from 2015/1/21 to 2015/1/26 13:34:34 are compared with corresponding S1 (2015/1/26 13:34:34, first sub-swath masked out) and RS2 FQ (2015/1/26 13:39:44) scenes in Figure 9(a1-e1) and (a2-e2), and those from 2015/1/21 to 2015/1/26 07:02:45 are compared with the corresponding RS2 SCWA (2015/1/26 06:59:28) scene in Figure 9(a3-e3). Also, Figure 10 additionally shows close-ups of parts of the comparison in the RS2 SCWA scene, showing more spatial details of the smaller and narrower features of deformation parcels and their correspondence to the classifications. Similar observations can be made on the S1 scene (not shown).

During the period of ice parcel tracking (2015/01/21 - 2015/01/26), a storm with a peak wind speed of $10.8 \mathrm{~m} / \mathrm{s}$ passed through Fram Strait (storm M1, 21 to 22 January (Cohen et al., 2017)), and hit the area surrounding the N-ICE2015 research camp (Cohen et al., 2017; Graham et al., 2019). The storm first pushed ice northward and thus compacting the ice pack, causing ice deformation along re-frozen leads and cracking thicker ice floes. It then transported ice southward towards the ice edge in the second phase, generating strong divergence and opening along the same leads and cracks. Following the storm passage, newly opened leads rapidly re-froze following the returning of dry and cold conditions, creating new ice (Itkin et al., 2017; Graham et al., 2019). Accordingly, the parcels (Figure 9, row (b)) indicate major presence of new and deformed ice concentrated along several LKFs. Divergence zones with new lead ice prevail, but are mixed with convergence zones where 
https://doi.org/10.5194/tc-2021-119

Preprint. Discussion started: 26 April 2021

(c) Author(s) 2021. CC BY 4.0 License.
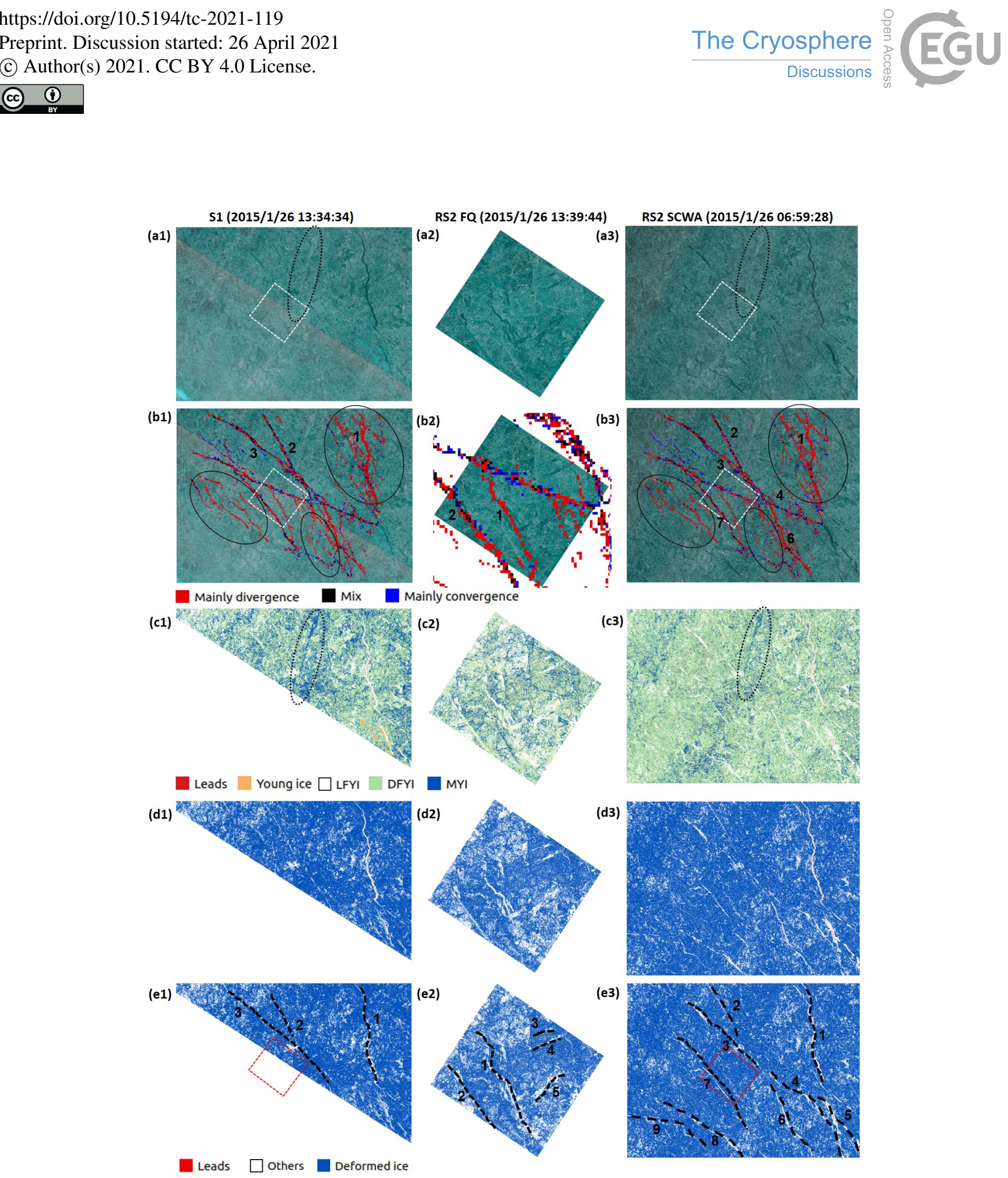

Figure 9. Comparison of classification results and deformation parcels. Row (a) SAR RGB composites; row (b) SAR RGB composites and corresponding deformation parcels; rows (c) and (d) ice type and deformation state classification results using the GIA classifier re-trained using corresponding training sets; row (e) same as (d), with primary linear stripes of the 'others' class marked and numbered. The position of the RS2 FQ scene is shown as white or red rectangles in the wide-swath scenes. 
https://doi.org/10.5194/tc-2021-119

Preprint. Discussion started: 26 April 2021

(c) Author(s) 2021. CC BY 4.0 License.
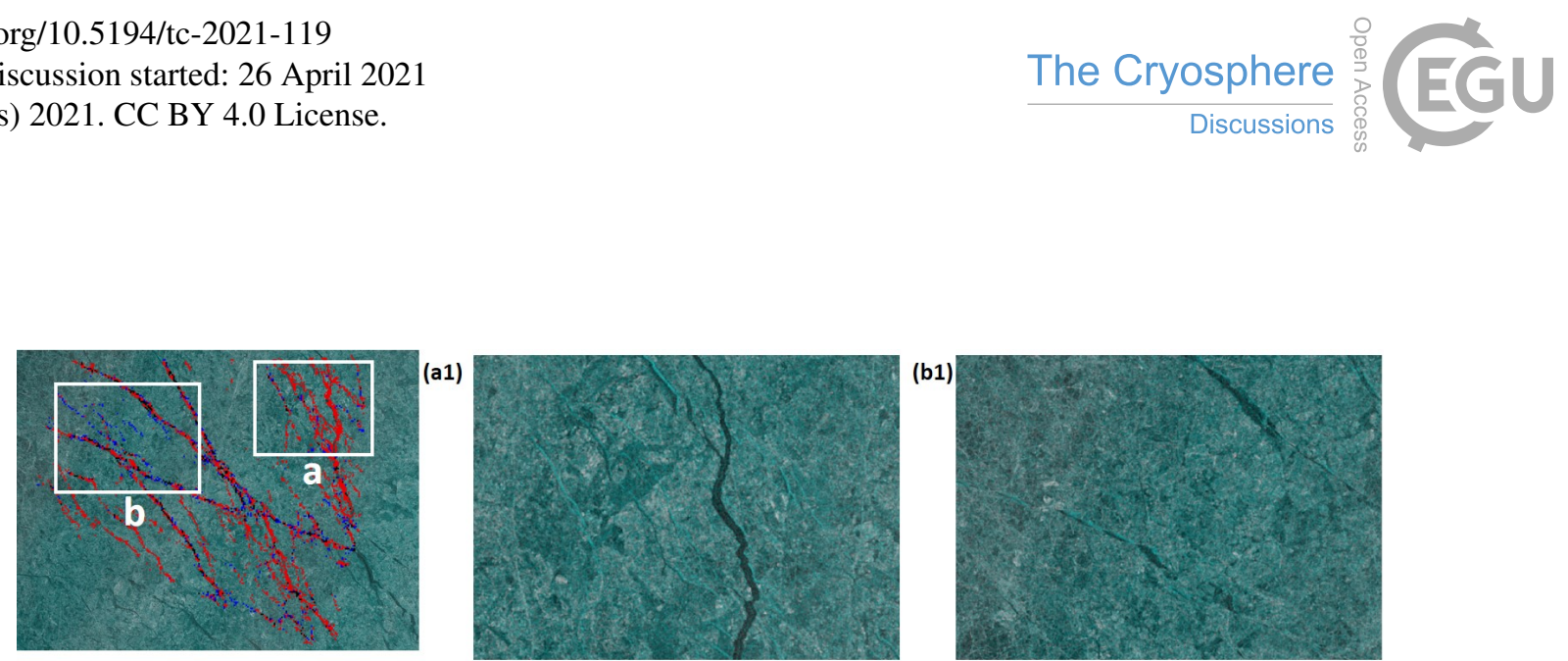

(a2)
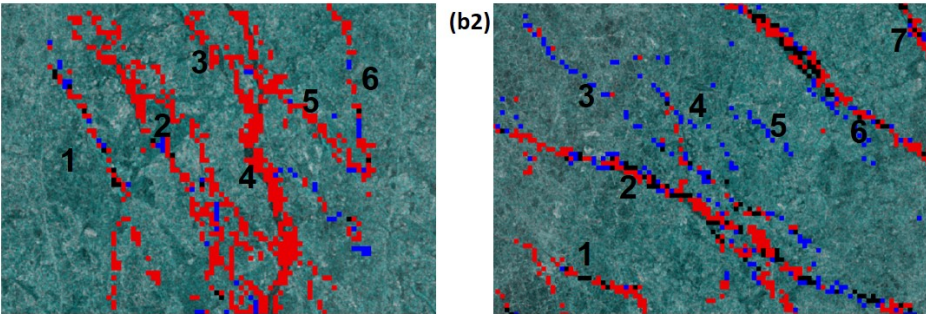

(a3)
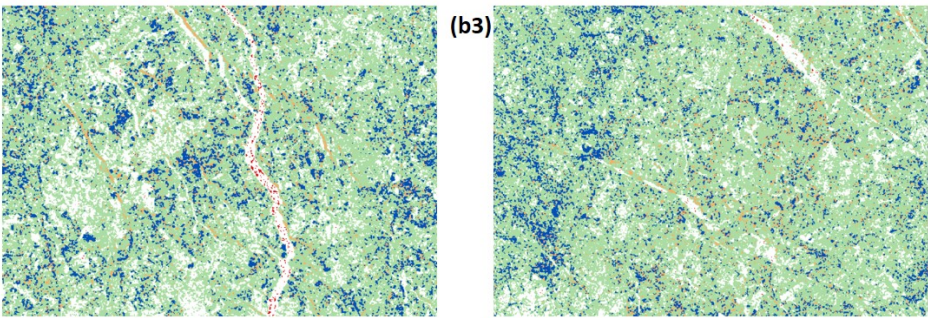

(a4)
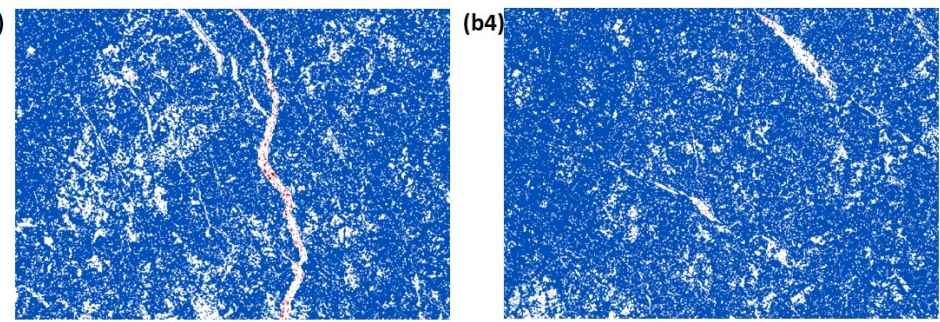

(a5)
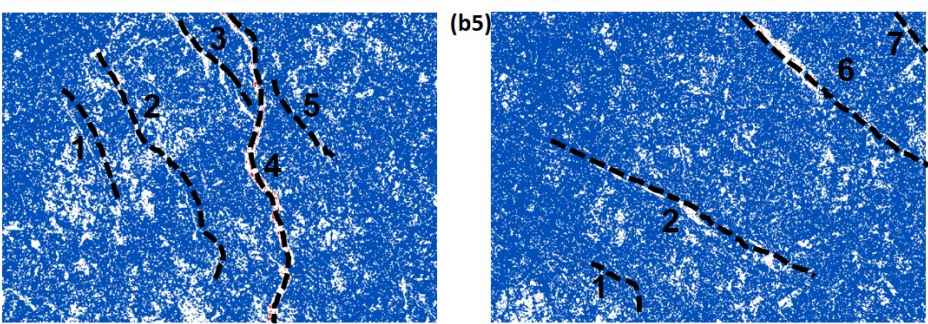

Figure 10. Close-up comparison of classification results and deformation parcels for the RS2 SCWA scene. Color scales are the same as Figure 9.

375 deformed ice is expected to be produced, mainly in the middle of the maps (Figure 9(b1) and (b3)). The north-eastern and southern parts of the maps experienced mainly ice divergence, marked by solid ellipses. 
https://doi.org/10.5194/tc-2021-119

Preprint. Discussion started: 26 April 2021

(c) Author(s) 2021. CC BY 4.0 License.

(c) (i)

It is difficult to interpret direct correspondence between the deformation parcels and the classification maps, as areas of ice divergence and convergence do not directly correspond to specific ice types, and the deformation parcel maps only represent ice motion accumulated in the 6-day period. Still, observations can be made for: 1 . whether the classified ice types correctly correspond to ice divergence or convergence indicated by the deformation parcels, and 2. if the classification maps and deformation parcels each identifies visible deformation features not shown by the other.

1. Classification results. An overall examination of classification maps of deformation states (Figure 9(d1-d3)) shows that 'deformed ice' is pervasive within the scenes. The same can be concluded from visual examination of the scenes (Figure 9(a)) and is reported by N-ICE2015 records and observations (Itkin et al., 2017; Granskog et al., 2018; Graham et al., 2019). However, the true percentage of deformation in the scene cannot be retrieved or confirmed using available data due to the inclusion of ice surface with other rough surface features in the DFYI class, as well as ambiguity between DFYI and MYI, as mentioned above. The deformed ice class (three-class scheme) is comprised of mainly DFYI (5-class scheme, Figure 9(c1-c3)). MYI also contributes significantly, capturing many bright deformation features, most prominently a linear feature of MYI on top of the RS2 SCWA and S1 scenes, marked by dotted ellipses (Figure 9(a1), (a3) and (c1), (c3)). In the six-day period, this old refrozen lead (likely covered by frost flowers) did not undergone any detectable convergence or divergence, and is therefore not represented in the deformation parcels.

On the other hand, many LKFs in the 'others' class (three-class scheme) are visible in the classification maps of deformation states (white in Figure 9(d1-d3)), the primary ones marked by dashed lines and numbered in Figure 9(e1-e3). These are comprised of mostly LFYI in re-frozen leads (five-class scheme, Figure 9(c1-c3)), which can physically correspond to level young ice or FYI, as mentioned above. Most of these level ice areas also appear in the deformation parcel maps (Figure 9(b1b3)), where they are numbered accordingly. Lines 5, 8 and 9 in Figure 9(e3) do not appear in the deformation parcel maps (Figure 9(b3)) as they are out of the maps' areal coverage. Open water areas in line 1 in Figure 9(e1) and (e3) are correctly classified as leads (red in Figure 9(c1-d1) and (c3-d3)). The RS2 FQ scenes shows similar overall distribution of ice types as wide-swath scenes, but its higher spatial resolution more clearly picks up some more visible ice openings with more spatial details (lines 1, 3, 4 and 5 in Figure 9(e2)), compared to (e3)).

2. Deformation parcels. For the deformation parcels, the most prominent (widest) features tend to have more recognizable correspondence to features delineated by the classifications. These are either mostly ice divergence mixed with convergence, or exclusively divergence, in both time stamps. For example, the end states of lines 2 and 3 in Figure 9(b1) and (b3) are shown to be dominated by LFYI and young ice, surrounded by DFYI (Figure 9(c1 and (c3)), corresponding well to the co-authors' field experience of deformation occurrence at the interface between young ice and older ice, as mentioned above. It should be noted that the pixels showing 'mostly convergence' are derived from values accumulated in the 6-day period, and therefore cannot represent deformation features which have been accumulated over longer periods.

The above mentioned areas indicating mainly ice divergence (Figure 9(b1) and (b3), solid ellipses, excluding the major lead, i.e. line 1), are less recognizable in the classification maps of deformation states. Ice type classifications indicate these are narrower and smaller leads occupied mostly by LFYI and young ice. One of these areas is more clearly shown in Figure 10(a1-a5), 
https://doi.org/10.5194/tc-2021-119

Preprint. Discussion started: 26 April 2021

(c) Author(s) 2021. CC BY 4.0 License.

(c) (i)

where the visible LKFs are delineated and numbered, in which lines 1-5 are identified by both the classification and deformation parcels. Figure 10(b1-b5) shows the classifications for areas where deformation parcels indicate prominent presence of ice convergence. The thinner linear stripes of ice convergence (lines 3, 4 and 5) do not correspond to visible features in the classifications, while lines 2, 6 and 7 with extensive coverage of blue and black colors (ice convergence and mix) are classified as mostly LFYI and young ice which are interrupted by DFYI sections.

To summarize, the classifications capture ice openings with the 'leads' and 'others' classes (leads, young ice and LFYI in the five-class scheme) that correspond well with areas of ice divergence. This good correspondence is also partly due to the surface features created by ice divergence being more spatially confined. On the other hand, the 'deformed ice' class includes a mix of DFYI and MYI that is spatially wide-spread, where the true proportions of deformed ice cannot be reliably verified, and hence has limited correspondence with areas of ice convergence from the deformation parcels. This is both due to the accumulation of ice deformation in a period longer than the parcel tracking, and also to the limitation of the classifier working only with $\mathrm{HH}$ and HV channels of the C-band sensors. The RS2 FQ scenes performs similarly to the wide-swath scenes when the re-trained GIA classifier is applied, but can serve to preserve more spatial details of surface features. The capacity of the classification results to identify these surface features (mainly ice divergence) in the deformation parcels serves as another validation of the re-trained GIA classifier when applied to our study area.

\subsection{Limitations and future steps}

This study is a first step towards the goal of Arctic-wide ice deformation detection based on a consistent classification method applicable to multiple SAR platforms, and thus investigates the cross-platform application of the GIA classifier in a local setting. Thus, we work within the limitations of both the classifier and the characteristics of $\mathrm{HH}$ and $\mathrm{HV}$ channels of the Cband SAR sensors which affects complete derivation of ice deformation, as summarized above. Very limited ground truth of ice types from in-situ data is available for re-training and validation, hence the heavy preference given to the N-ICE2015 data to utilize the co-authors' expert knowledge on ice conditions in the campaign.

This study expands the application of the GIA classifier from S1 to RS2 data, both in C-band. Additional studies will be conducted seeking further expansion of its application to more SAR platforms, e.g. X- and L-band SAR, which provides potential for better separation between the ambiguous class pairs in the current classification. IA dependency in SAR data with these different frequencies needs to be rigorously examined and validated. It is expected that frequency-and-region-specific re-training will still be essential for deformation detection using the altered classifier for different sensors, as SAR intensity contrast between level and deformed ice is sensitive to SAR properties as well as ice properties that vary cross regions, e.g. small-scale roughness and ice volume structure (Dierking and Dall, 2007). The inclusion of more features into the classification is also desirable, e.g. polarimetric features sensitive to sea ice deformation (e.g. Ressel et al., 2016; Park et al., 2019), and also texture features (e.g. Park et al., 2020; Lohse et al., 2021). For example, the recent study by Lohse et al. (2021) investigated the IA dependencies of common texture features, and demonstrated that incorporating these features into ice type classification can improve the separation of young ice and MYI, as well as the generalized classification of open water areas. However, 
https://doi.org/10.5194/tc-2021-119

Preprint. Discussion started: 26 April 2021

(C) Author(s) 2021. CC BY 4.0 License.

(c) (i)

the improvement comes at the cost of reduced spatial resolution due to the applied texture windows. Further integration of

IA dependency into classifiers other than the Bayesian classifier is also desirable in future studies to seek better classification performances. Finally, successful cross-platform application of an optimal classification method can be used to create a reliable time series of classification maps which can be better used to derive and compare with ice deformation products.

\section{Conclusions}

This study demonstrates that S1 and RS2 data produce similar IA dependencies of different ice types. However, in our study area and based on the GIA classifier, the direct transfer of training between S1 and RS2 SCWA data is not applicable due to the difference in noise floor configurations, which affects classification performance especially for the leads class. Datasetand region-specific re-training is found to be necessary, and the GIA classifier re-trained specific to S1, RS2 SCWA and RS2 FQ datasets produces similar and improved classification performances compared to the original classifier. The cross-platform application of the GIA classifier extends usable C-band SAR data over the study area from 2015 to present (S1) to 2010 to present (RS2). This study further provides reference to future cross-platform application of training between S1 and RS2 so valuable training sets can be better utilized, e.g. with proper re-training or direct application when leads are not of interest.

The comparison between deformation parcels and classification results with dataset-specific local re-training shows the best correspondence in leads with open water and nilas, young ice or LFYI, as prominent ice openings created by divergence following the storm passage are in linear forms and well captured by both analyses. The DFYI and MYI classes in the classification results do not clearly correspond to linear ice convergence zones indicated by deformation parcels, both due to the limitation of the classification method used and the difference in the period of deformation accumulation represented by both datasets. RS2 FQ scenes can be used to provide more spatial details in delineating deformation features. The comparison with deformation parcels further serves to partially validate the classification results.

In summary, through the cross-platform application of the GIA classifier, this study demonstrates the potentials and obstacles in the transfer of training between S1 and RS2 data, as well as in the use of the classification to separate level and deformed ice. We expect future development of the classifier and the inclusion of additional datasets will enable the possibility of large-scale monitoring of ice deformation merely from the classification of widely available satellite SAR data.

Author contributions. Dr. Polona Itkin acquired funding for this study. Dr. Polona Itkin, Dr. Malin Johansson and Ass. Prof. Anthony Paul Doulgeris were involved in project administration and supervision. All co-authors were involved in the conceptualization of the study. Dr. Wenkai Guo was responsible for data curation, methodology designing, formal analysis, and result visualization. Dr. Johannes Lohse provided his codes and knowledge of the GIA classifier. Dr. Polona Itkin produced the deformation parcel maps for comparison with the classification results. Dr. Wenkai Guo prepared the manuscript, with contributions from all co-authors in reviewing and editing.

Competing interests. No competing interests are present. 
https://doi.org/10.5194/tc-2021-119

Preprint. Discussion started: 26 April 2021

(C) Author(s) 2021. CC BY 4.0 License.

(c) (1)

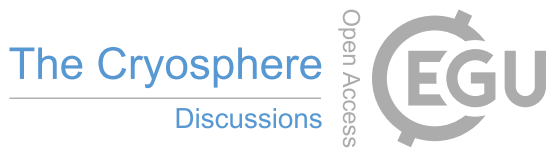

Acknowledgements. RADARSAT-2 data was provided by NSC/KSAT under the Norwegian-Canadian Radarsat agreement 2015 and 2019.

475 Sentinel-1 and Sentinel-2 data $\odot$ Copernicus data (2015 and 2019). Landsat-8 images courtesy of the U.S. Geological Survey. The NICE2015 expedition was supported by the Centre of Ice, Climate and Ecosystems (ICE), Norwegian Polar Institute, Troms $\varnothing$, Norway. The authors also extend their thanks to all who participated in the N-ICE2015 campaign, including personnel from the Norwegian Polar Institute, as well as many partner organizations and the R/V Lance crew. They would like to thank the personnel from UiT The Arctic University of Norway and the Norwegian Polar Institute who made the co-located satellite image acquisitions possible, M. König from NPI and T. Kræmer and A.M. Johansson from UiT.

This work was supported by the Research Council of Norway (RCN) projects: Sea Ice Deformation and Snow for an Arctic in Transition (SIDRiFT) (287871), Center for Integrated Remote Sensing and Forecasting for Arctic Operations (CIRFA) (237906), and Project Oil spill and newly formed sea ice detection, characterization, and mapping in the Barents Sea using remote sensing by SAR (OIBSAR) (280616). 
https://doi.org/10.5194/tc-2021-119

Preprint. Discussion started: 26 April 2021

(c) Author(s) 2021. CC BY 4.0 License.

(c) (i)

\section{References}

Arntsen, A. E., Song, A. J., Perovich, D. K., and Richter-Menge, J. A.: Observations of the summer breakup of an Arctic sea ice cover, Geophysical Research Letters, 42, 8057-8063, https://doi.org/https://doi.org/10.1002/2015GL065224, https://doi.org/10.1002/ 2015GL065224, 2015.

Asplin, M. G., Galley, R., Barber, D. G., and Prinsenberg, S.: Fracture of summer perennial sea ice by ocean swell as a result of Arctic storms, Journal of Geophysical Research: Oceans, 117, 1-12, https://doi.org/10.1029/2011JC007221, 2012.

Assmy, P., Fernández-Méndez, M., Duarte, P., Meyer, A., Randelhoff, A., Mundy, C. J., Olsen, L. M., Kauko, H. M., Bailey, A., Chierici, M., Cohen, L., Doulgeris, A. P., Ehn, J. K., Fransson, A., Gerland, S., Hop, H., Hudson, S. R., Hughes, N., Itkin, P., Johnsen, G., King, J. A., Koch, B. P., Koenig, Z., Kwasniewski, S., Laney, S. R., Nicolaus, M., Pavlov, A. K., Polashenski, C. M., Provost, C., Rösel, A., Sandbu, M., Spreen, G., Smedsrud, L. H., Sundfjord, A., Taskjelle, T., Tatarek, A., Wiktor, J., Wagner, P. M., Wold, A., Steen, H., and Granskog, M. A.: Leads in Arctic pack ice enable early phytoplankton blooms below snow-covered sea ice, Scientific Reports, 7, 1-9, https://doi.org/10.1038/srep40850, 2017.

Barber, D. G., Hanesiak, J. M., and Yackel, J. J.: Sea ice, radarsat-1 and arctic climate processes: A review and update, Canadian Journal of Remote Sensing, 27, 51-61, https://doi.org/10.1080/07038992.2001.10854919, 2001.

Bouillon, S. and Rampal, P.: On producing sea ice deformation data sets from SAR-derived sea ice motion, The Cryosphere, 9, 663-673, https://doi.org/10.5194/tc-9-663-2015, 2015.

Cafarella, S. M., Scharien, R., Geldsetzer, T., Howell, S., Haas, C., Segal, R., and Nasonova, S.: Estimation of Level and Deformed FirstYear Sea Ice Surface Roughness in the Canadian Arctic Archipelago from C- and L-Band Synthetic Aperture Radar, Canadian Journal of Remote Sensing, 45, 457-475, https://doi.org/10.1080/07038992.2019.1647102, https://doi.org/10.1080/07038992.2019.1647102, 2019.

Casey, J. A., Beckers, J., Busche, T., and Haas, C.: Towards the retrieval of multi-year sea ice thickness and deformation state from polarimetric C- and X-band SAR observations, in: International Geoscience and Remote Sensing Symposium (IGARSS), pp. 1190-1193, IEEE, https://doi.org/10.1109/IGARSS.2014.6946644, 2014.

Cavalieri, D. J., Markus, T., Ivanoff, A., Liu, A. K., and Zhao, Y.: AMSR-E/Aqua Daily L3 6.25 km Sea Ice Drift Polar Grids, Version 1, https://doi.org/https://doi.org/10.5067/AMSR-E/AE_SID.001, 2011.

Cohen, L., Hudson, S. R., Walden, V. P., Graham, R. M., and Granskog, M. A.: Meteorological conditions in a thinner Arctic sea ice regime from winter to summer during the Norwegian Young sea ice expedition (N-ICE2015), Journal of Geophysical Research, 122, 7235-7259, https://doi.org/10.1002/2016JD026034, 2017.

Cole, S. T., Toole, J. M., Lele, R., Timmermans, M. L., Gallaher, S. G., Stanton, T. P., Shaw, W. J., Hwang, B., Maksym, T., Wilkinson, J. P., Ortiz, M., Graber, H., Rainville, L., Petty, A. A., Farrell, S. L., Richter-Menge, J. A., and Haas, C.: Ice and ocean velocity in the Arctic marginal ice zone: Ice roughness and momentum transfer, Elementa, 5, https://doi.org/10.1525/elementa.241, 2017.

Dabboor, M., Montpetit, B., Howell, S., and Haas, C.: Improving sea ice characterization in dry ice winter conditions using polarimetric parameters from C- and L-Band SAR data, Remote Sensing, 9, https://doi.org/10.3390/rs9121270, 2017.

Dierking, W.: Technical Assistance for the Deployment of Airborne SAR and Geophysical Measurements during the ICESAR 2007; Final Report-Part 2: Sea Ice, Report, ESA-ESTEC Contract No. 20655/07/NL/CB, 2008.

Dierking, W.: Mapping of Different Sea Ice Regimes Using Images From Sentinel-1 and ALOS Synthetic Aperture Radar, IEEE Transactions on Geoscience and Remote Sensing, 48, 1045-1058, https://doi.org/10.1109/TGRS.2009.2031806, 2010. 
https://doi.org/10.5194/tc-2021-119

Preprint. Discussion started: 26 April 2021

(c) Author(s) 2021. CC BY 4.0 License.

(c) (i)

Dierking, W. and Dall, J.: Sea-ice deformation state from synthetic aperture radar imagery - Part I: Comparison of C- and L-B and and different polarization, IEEE Transactions on Geoscience and Remote Sensing, 45, 3610-3621, https://doi.org/10.1109/TGRS.2007.903711, 2007.

Dybkjaer, G.: Medium Resolution Sea Ice Drift Product User Manual, Tech. rep., 2018.

European Space Agency: SNAP - ESA Sentinel Application Platform v7.0.4, http://step.esa.int, 2020.

Fernández-Méndez, M., Olsen, L. M., Kauko, H. M., Meyer, A., Rösel, A., Merkouriadi, I., Mundy, C. J., Ehn, J. K., Johansson, A. M., Wagner, P. M., Ervik, Å., Sorrell, B. K., Duarte, P., Wold, A., Hop, H., and Assmy, P.: Algal hot spots in a changing Arctic Ocean: Sea-ice ridges and the snow-ice interface, Frontiers in Marine Science, 5, https://doi.org/10.3389/fmars.2018.00075, 2018.

Gatti, A. and Bertolini, A.: Sentinel-2 Products Specification Document, S2-PDGS-TAS-DI-PSD, Issue: 13.1, 2015.

Gegiuc, A., Similä, M., Karvonen, J., Lensu, M., Mäkynen, M., and Vainio, J.: Estimation of degree of sea ice ridging based on dual-polarized C-band SAR data, The Cryosphere, 12, 343-364, https://doi.org/10.5194/tc-12-343-2018, 2018.

Gill, J. P. S., Yackel, J. J., Geldsetzer, T., and Fuller, M. C.: Sensitivity of C-band synthetic aperture radar polarimetric parameters to snow thickness over landfast smooth first-year sea ice, Remote Sensing of Environment, 166, 34-49, https://doi.org/https://doi.org/10.1016/j.rse.2015.06.005, http://www.sciencedirect.com/science/article/pii/S0034425715300365, 2015.

Gorelick, N., Hancher, M., Dixon, M., Ilyushchenko, S., Thau, D., and Moore, R.: Google Earth Engine: Planetary-scale geospatial analysis for everyone, Remote Sensing of Environment, 202, 18-27, https://doi.org/https://doi.org/10.1016/j.rse.2017.06.031, http://www. sciencedirect.com/science/article/pii/S0034425717302900, 2017.

Gradinger, R., Bluhm, B., and Iken, K.: Arctic sea-ice ridges - Safe heavens for sea-ice fauna during periods of extreme ice melt?, Deep Sea Research Part II: Topical Studies in Oceanography, 57, 86-95, https://doi.org/https://doi.org/10.1016/j.dsr2.2009.08.008, https://www. sciencedirect.com/science/article/pii/S0967064509002513, 2010.

Graham, R. M., Itkin, P., Meyer, A., Sundfjord, A., Spreen, G., Smedsrud, L. H., Liston, G. E., Cheng, B., Cohen, L., Divine, D., Fer, I., Fransson, A., Gerland, S., Haapala, J., Hudson, S. R., Johansson, A. M., King, J., Merkouriadi, I., Peterson, A. K., Provost, C., Randelhoff, A., Rinke, A., Rösel, A., Sennéchael, N., Walden, V. P., Duarte, P., Assmy, P., Steen, H., and Granskog, M. A.: Winter storms accelerate the demise of sea ice in the Atlantic sector of the Arctic Ocean, Scientific Reports, 9, https://doi.org/10.1038/s41598-019-45574-5, 2019.

Granskog, M. A., Rösel, A., Dodd, P. A., Divine, D., Gerland, S., Martma, T., and Leng, M. J.: Snow contribution to firstyear and second-year Arctic sea ice mass balance north of Svalbard, Journal of Geophysical Research: Oceans, 122, 2539-2549, https://doi.org/https://doi.org/10.1002/2016JC012398, https://doi.org/10.1002/2016JC012398, 2017.

Granskog, M. A., Fer, I., Rinke, A., and Steen, H.: Atmosphere-Ice-Ocean-Ecosystem Processes in a Thinner Arctic Sea Ice Regime: The Norwegian Young Sea ICE (N-ICE2015) Expedition, Journal of Geophysical Research: Oceans, 123, 1586-1594, https://doi.org/10.1002/2017JC013328, 2018.

Herzfeld, U. C., Hunke, E. C., McDonald, B. W., and Wallin, B. F.: Sea ice deformation in Fram Strait - Comparison of CICE simulations with analysis and classification of airborne remote-sensing data, Cold Regions Science and Technology, 117, 19-33, https://doi.org/10.1016/j.coldregions.2015.05.001, http://dx.doi.org/10.1016/j.coldregions.2015.05.001, 2015.

Howell, S. E., Komarov, A. S., Dabboor, M., Montpetit, B., Brady, M., Scharien, R. K., Mahmud, M. S., Nandan, V., Geldsetzer, T., and Yackel, J. J.: Comparing L- and C-band synthetic aperture radar estimates of sea ice motion over different ice regimes, Remote Sensing of Environment, 204, 380-391, https://doi.org/10.1016/j.rse.2017.10.017, https://doi.org/10.1016/j.rse.2017.10.017, 2018.

Hutchings, J. K., Roberts, A., Geiger, C. A., and Richter-Menge, J.: Spatial and temporal characterization of sea-ice deformation, Annals of Glaciology Glaciol, 52, 360-368, https://doi.org/10.3189/172756411795931769, 2011. 
https://doi.org/10.5194/tc-2021-119

Preprint. Discussion started: 26 April 2021

(c) Author(s) 2021. CC BY 4.0 License.

(c) (i)

Hwang, B., Wilkinson, J., Maksym, T., Graber, H. C., Schweiger, A., Horvat, C., Perovich, D. K., Arntsen, A. E., Stanton, T. P., Ren, J., and Wadhams, P.: Winter-to-summer transition of Arctic sea ice breakup and floe size distribution in the Beaufort Sea, Elementa: Science of the Anthropocene, 5, https://doi.org/10.1525/elementa.232, https://doi.org/10.1525/elementa.232, 2017.

Itkin, P., Spreen, G., Cheng, B., Doble, M., Girard-Ardhuin, F., Haapala, J., Hughes, N., Kaleschke, L., Nicolaus, M., and Wilkinson, J.: Thin ice and storms: Sea ice deformation from buoy arrays deployed during N-ICE2015, Journal of Geophysical Research: Oceans, 122, 4661-4674, https://doi.org/https://doi.org/10.1002/2016JC012403, https://doi.org/10.1002/2016JC012403, 2017.

Itkin, P., Spreen, G., Hvidegaard, S. M., Skourup, H., Wilkinson, J., Gerland, S., and Granskog, M. A.: Contribution of Deformation to Sea Ice Mass Balance: A Case Study From an N-ICE2015 Storm, Geophysical Research Letters, 45, 789-796, https://doi.org/10.1002/2017GL076056, 2018.

Johansson, A. M., King, J. A., Doulgeris, A. P., Gerland, S., Singha, S., Spreen, G., and Busche, T.: Combined observations of Arctic sea ice with near-coincident colocated X-band, C-band, and L-band SAR satellite remote sensing and helicopter-borne measurements, Journal of Geophysical Research: Oceans, 122, 669-691, https://doi.org/10.1002/2016JC012273, https://doi.org/10.1002/2016JC012273, 2017.

Komarov, A. S. and Barber, D. G.: Sea ice motion tracking from sequential dual-polarization RADARSAT-2 images, IEEE Transactions on Geoscience and Remote Sensing, 52, 121-136, https://doi.org/10.1109/TGRS.2012.2236845, 2014.

Korosov, A. A. and Rampal, P.: A combination of feature tracking and pattern matching with optimal parametrization for sea ice drift retrieval from SAR data, Remote Sensing, 9, https://doi.org/10.3390/rs9030258, 2017.

Kwok, R.: The RADARSAT Geophysical Processor System BT - Analysis of SAR Data of the Polar Oceans: Recent Advances, pp. 235-257, Springer Berlin Heidelberg, Berlin, Heidelberg, https://doi.org/10.1007/978-3-642-60282-5_11, https://doi.org/10.1007/ 978-3-642-60282-5\{_\}11, 1998.

Landrum, L. and Holland, M. M.: Extremes become routine in an emerging new Arctic, Nature Climate Change, 10, 1108-1115, https://doi.org/10.1038/s41558-020-0892-z, https://doi.org/10.1038/s41558-020-0892-z, 2020.

Lavergne, T.: Low Resolution Sea Ice Drift Product User's Manual, Tech. rep., 2016.

580 Lehtiranta, J., Siiriä, S., and Karvonen, J.: Comparing C- and L-band SAR images for sea ice motion estimation, The Cryosphere, 9, 357-366, https://doi.org/10.5194/tc-9-357-2015, 2015.

Liston, G. E., Polashenski, C., Rösel, A., Itkin, P., King, J., Merkouriadi, I., and Haapala, J.: A Distributed SnowEvolution Model for Sea-Ice Applications (SnowModel), Journal of Geophysical Research: Oceans, 123, 3786-3810, https://doi.org/https://doi.org/10.1002/2017JC013706, https://doi.org/10.1002/2017JC013706, 2018.

Liu, H., Guo, H., and Zhang, L.: SVM-Based Sea Ice Classification Using Textural Features and Concentration From RADARSAT2 Dual-Pol ScanSAR Data, IEEE Journal of Selected Topics in Applied Earth Observations and Remote Sensing, 8, 1601-1613, https://doi.org/10.1109/JSTARS.2014.2365215, 2015.

Lohse, J., Doulgeris, A. P., and Dierking, W.: Mapping sea-ice types from Sentinel-1 considering the surface-type dependent effect of incidence angle, Annals of Glaciology, pp. 1-11, https://doi.org/10.1017/aog.2020.45, 2020.

590 Lohse, J., Doulgeris, A. P., and Dierking, W.: Incident Angle Dependence of Sentinel-1 Texture Features for Sea Ice Classification (in review), Remote Sensing, 13, https://www.mdpi.com/2072-4292/13/4/552, 2021.

MacDonald Dettwiler Assoc. Ltd. (MDA): Sentinel-1 Product Definition, S1-RS-MDA-52-7440, Issue/Revision: 2/3, 2016.

MacDonald Dettwiler Assoc. Ltd. (MDA): RADARSAT-2 Product Description, RN-SP-52-1238, Issue 1/14, 2018. 
https://doi.org/10.5194/tc-2021-119

Preprint. Discussion started: 26 April 2021

(c) Author(s) 2021. CC BY 4.0 License.

(c) (i)

Mahmud, M. S., Geldsetzer, T., Howell, S. E., Yackel, J. J., Nandan, V., and Scharien, R. K.: Incidence angle dependence of HH-polarized C- A nd L-band wintertime backscatter over arctic sea ice, IEEE Transactions on Geoscience and Remote Sensing, 56, 6686-6698, https://doi.org/10.1109/TGRS.2018.2841343, 2018.

Mäkynen, M. and Juha, K.: Incidence Angle Dependence of First-Year Sea Ice Backscattering Coefficient in Sentinel-1 SAR Imagery over the Kara Sea, IEEE Transactions on Geoscience and Remote Sensing, 55, 6170-6181, https://doi.org/10.1109/TGRS.2017.2721981, 2017.

Mäkynen, M. P., Manninen, A. T., Similä, M. H., Karvonen, J. A., and Hallikainen, M. T.: Incidence angle dependence of the statistical properties of C-band HH-polarization backscattering signatures of the Baltic Sea ice, IEEE Transactions on Geoscience and Remote Sensing, 40, 2593-2605, https://doi.org/10.1109/TGRS.2002.806991, 2002.

Marsan, D., Stern, H., Lindsay, R., and Weiss, J.: Scale dependence and localization of the deformation of arctic sea ice, Physical Review Letters, 93, 3-6, https://doi.org/10.1103/PhysRevLett.93.178501, 2004.

Martin, T., Tsamados, M., Schröder, D., and Feltham, D. L.: Journal of Geophysical Research : Oceans in Arctic Ocean surface stress : A model study, Journal of Geophysical Research: Oceans, 121, 1931-1952, https://doi.org/10.1002/2015JC011186.Received, 2016.

Moen, M. A., Doulgeris, A. P., Anfinsen, S. N., Renner, A. H., Hughes, N., Gerland, S., and Eltoft, T.: Comparison of feature based segmentation of full polarimetric SAR satellite sea ice images with manually drawn ice charts, The Cryosphere, 7, 1693-1705, https://doi.org/10.5194/tc-7-1693-2013, 2013.

Murashkin, D., Spreen, G., Huntemann, M., and Dierking, W.: Method for detection of leads from Sentinel-1 SAR images, Annals of Glaciology, 59, 124-136, https://doi.org/10.1017/aog.2018.6, 2018.

Northrop, A.: IDEAS - LANDSAT Products Description Document, IDEAS-VEG-SRV-REP-1320, Issue: 6.0, 2015.

Onstott, R. G.: SAR and Scatterometer Signatures of Sea Ice, https://doi.org/https://doi.org/10.1029/GM068p0073, https://doi.org/10.1029/ GM068p0073, 1992.

OSI SAF: The Sea ice type product of the EUMETSAT Ocean and Sea Ice Satellite Application Facility (OSI SAF), www.osi-saf.org, 2015.

Park, J., Won, J., Korosov, A. A., Babiker, M., and Miranda, N.: Textural Noise Correction for Sentinel-1 TOPSAR Cross-Polarization Channel Images, IEEE Transactions on Geoscience and Remote Sensing, 57, 4040-4049, https://doi.org/10.1109/TGRS.2018.2889381, 2019.

Park, J. W., Korosov, A. A., Babiker, M., Won, J. S., Hansen, M. W., and Kim, H. C.: Classification of sea ice types in Sentinel-1 synthetic aperture radar images, The Cryosphere, 14, 2629-2645, https://doi.org/10.5194/tc-14-2629-2020, 2020.

Rampal, P., Weiss, J., and Marsan, D.: Positive trend in the mean speed and deformation rate of Arctic sea ice, 1979-2007, Journal of Geophysical Research: Oceans, 114, 1-14, https://doi.org/10.1029/2008JC005066, 2009.

Rampal, P., Weiss, J., Dubois, C., and Campin, J. M.: IPCC climate models do not capture Arctic sea ice drift acceleration: Consequences in terms of projected sea ice thinning and decline, Journal of Geophysical Research: Oceans, 116, 1-17, https://doi.org/10.1029/2011JC007110, 2011.

Raney, R. K., Luscombe, A. P., Langham, E. J., and Ahmed, S.: RADARSAT (SAR imaging), Proceedings of the IEEE, 79, 839-849, https://doi.org/10.1109/5.90162, 1991.

Ressel, R., Singha, S., Lehner, S., Rösel, A., and Spreen, G.: Investigation into Different Polarimetric Features for Sea Ice Classification Using X-Band Synthetic Aperture Radar, IEEE Journal of Selected Topics in Applied Earth Observations and Remote Sensing, 9, 3131-3143, https://doi.org/10.1109/JSTARS.2016.2539501, 2016. 
https://doi.org/10.5194/tc-2021-119

Preprint. Discussion started: 26 April 2021

(c) Author(s) 2021. CC BY 4.0 License.

(c) (1)

Segal, R. A., Scharien, R. K., Cafarella, S., and Tedstone, A.: Characterizing winter landfast sea-ice surface roughness in the Canadian Arctic Archipelago using Sentinel-1 synthetic aperture radar and the Multi-angle Imaging SpectroRadiometer, Annals of Glaciology, pp. 1-15, https://doi.org/10.1017/aog.2020.48, 2020.

Singha, S., Johansson, M., Hughes, N., Hvidegaard, S. M., and Skourup, H.: Arctic Sea Ice Characterization Using Spaceborne Fully Polarimetric L-, C-, and X-Band SAR With Validation by Airborne Measurements, IEEE Transactions on Geoscience and Remote Sensing, 56, 3715-3734, https://doi.org/10.1109/TGRS.2018.2809504, 2018.

Singha, S., Johansson, A. M., and Doulgeris, A. P.: Robustness of SAR Sea Ice Type Classification Across Incidence Angles and Seasons at L-Band, IEEE Transactions on Geoscience and Remote Sensing, pp. 1-12, https://doi.org/10.1109/tgrs.2020.3035029, 2020.

Spreen, G., Kwok, R., and Menemenlis, D.: Trends in Arctic sea ice drift and role of wind forcing: 1992-2009, Geophysical Research Letters, 38, 1-6, https://doi.org/10.1029/2011GL048970, 2011.

640 Steer, A. D., Worby, A. P., and Heil, P.: Observed changes in sea-ice floe size distribution during early summer in the western Weddell Sea, Deep-sea Research Part II-topical Studies in Oceanography, 55, 933-942, 2008.

Sturm, M., Perovich, D. K., and Holmgren, J.: Thermal conductivity and heat transfer through the snow on the ice of the Beaufort Sea, Journal of Geophysical Research: Oceans, 107, https://doi.org/10.1029/2000jc000409, 2002.

The Mathworks Inc.: MATLAB R2020a, http://www.mathworks.com/, 2020.

645 Toyota, T., Takatsuji, S., and Nakayama, M.: Characteristics of sea ice floe size distribution in the seasonal ice zone, Geophysical Research Letters, 33, 2-5, https://doi.org/10.1029/2005GL024556, 2006.

Toyota, T., Ishiyama, J., and Kimura, N.: Measuring Deformed Sea Ice in Seasonal Ice Zones Using L-Band SAR Images, IEEE Transactions on Geoscience and Remote Sensing, pp. 1-21, https://doi.org/10.1109/TGRS.2020.3043335, 2020.

Van Rossum, G. and Drake, F. L.: Python 3 Reference Manual, CreateSpace, Scotts Valley, CA, United States, 2009.

650 Van Wychen, W., Vachon, P. W., Wolfe, J., and Biron, K.: Synergistic RADARSAT-2 and Sentinel-1 SAR Images for Ocean Feature Analysis, Canadian Journal of Remote Sensing, 45, 591-602, https://doi.org/10.1080/07038992.2019.1662284, https://doi.org/10.1080/07038992. 2019.1662284, 2019.

Zakhvatkina, N., Smirnov, V., and Bychkova, I.: Satellite SAR Data-based Sea Ice Classification: An Overview, Geosciences, 9, $152,2019$.

Zakhvatkina, N. Y., Alexandrov, V. Y., Johannessen, O. M., Sandven, S., and Frolov, I. Y.: Classification of sea ice types in ENVISAT synthetic aperture radar images, IEEE Transactions on Geoscience and Remote Sensing, 51, 2587-2600, https://doi.org/10.1109/TGRS.2012.2212445, 2013. 